\title{
Induction and Quantification of Excitability Changes in Human Cortical Networks
}

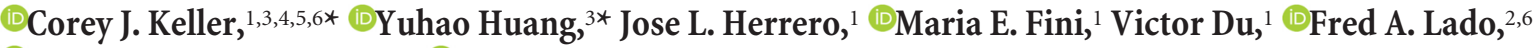 \\ DChristopher J. Honey, ${ }^{7}$ and ${ }^{1 D}$ Ashesh D. Mehta ${ }^{1}$ \\ Department of ${ }^{1}$ Neurosurgery, ${ }^{2}$ Neurology, Hofstra Northwell School of Medicine, and Feinstein Institute for Medical Research, Manhasset, New York \\ 11030, ${ }^{3}$ Department of Psychiatry and Behavioral Sciences, ${ }^{4}$ Stanford Neuroscience Institute, Stanford University, Stanford, California $94305,{ }^{5}$ Veterans \\ Affairs Palo Alto Healthcare System, Palo Alto, California, 94394, ${ }^{6}$ Departments of Neuroscience and Neurology, Albert Einstein College of Medicine, Bronx, \\ New York 10461, and 'Department of Psychological and Brain Sciences, Johns Hopkins University, Baltimore, Maryland 21218
}

How does human brain stimulation result in lasting changes in cortical excitability? Uncertainty on this question hinders the development of personalized brain stimulation therapies. To characterize how cortical excitability is altered by stimulation, we applied repetitive direct electrical stimulation in eight human subjects (male and female) undergoing intracranial monitoring. We evaluated single-pulse corticocortical-evoked potentials (CCEPs) before and after repetitive stimulation across prefrontal $(n=4)$, temporal $(n=1)$, and motor $(n=3)$ cortices. We asked whether a single session of repetitive stimulation was sufficient to induce excitability changes across distributed cortical sites. We found a subset of regions at which $10 \mathrm{~Hz}$ prefrontal repetitive stimulation resulted in both potentiation and suppression of excitability that persisted for at least $10 \mathrm{~min}$. We then asked whether these dynamics could be modeled by the prestimulation connectivity profile of each subject. We found that cortical regions (1) anatomically close to the stimulated site and (2) exhibiting high-amplitude CCEPs underwent changes in excitability following repetitive stimulation. We demonstrate high accuracy (72-95\%) and discriminability (81-99\%) in predicting regions exhibiting changes using individual subjects' prestimulation connectivity profile, and show that adding prestimulation connectivity features significantly improved model performance. The same features predicted regions of modulation following motor and temporal cortices stimulation in an independent dataset. Together, baseline connectivity profile can be used to predict regions susceptible to brain changes and provides a basis for personalizing brain stimulation.

Key words: CCEPs; corticocortical-evoked potentials; electrical stimulation; electrocorticography; neuromodulation; plasticity

Significance Statement

Brain stimulation is increasingly used to treat neuropsychiatric disorders by inducing excitability changes at specific brain regions. However, our understanding of how, when, and where these changes are induced is critically lacking. We inferred plasticity in the human brain after applying electrical stimulation to the brain's surface and measuring changes in excitability. We observed excitability changes in regions anatomically and functionally closer to the stimulation site. Those in responsive regions were accurately predicted using a classifier trained on baseline brain network characteristics. Finally, we showed that the excitability changes can potentially be monitored in real-time. These results begin to fill basic gaps in our understanding of stimulation-induced brain dynamics in humans and offer pathways to optimize stimulation protocols.

\section{Introduction}

Extensive preclinical studies have shown that high-frequency $(\sim 100$ $\mathrm{Hz}$ ) electrical brain stimulation increases neuronal excitability (Bliss

\footnotetext{
Received April 15, 2017; revised April 1, 2018; accepted April 9, 2018.

Author contributions: C.J.K., F.A.L., and A.D.M. designed research; C.J.K., J.L.H., M.E.F., and V.D. performed research; C.J.K., Y.H., and C.J.H. analyzed data; C.J.K., Y.H., J.L.H., C.J.H., and A.D.M. wrote the paper.

This work was funded the National Institute of Neurological Disorders and Stroke (F31NS080357-01 and T32GM007288 to (.J.K.), Stanford Society of Physician Scholars Collaborative Research Fellowship, and Alpha Omega Alpha Postgraduate Research Award. We thank Pierre Megevand and Erin Yeagle for help with technical considerations of the experimental design, and the patients who participated in this study as well as the nursing and physician staff of North Shore University Hospital.
}

and Lomo, 1973; Douglas, 1977; Skrede and Malthe-Sørenssen, 1981), whereas low-frequency $(\sim 1 \mathrm{~Hz})$ decreases neuronal excitability (Mulkey and Malenka, 1992). In humans, the effect of brain stimulation has been studied within the motor cortex by applying repetitive transcranial magnetic stimulation (rTMS).

\footnotetext{
The authors declare no competing financial interests.

${ }^{*}$ C.J.K. and Y.H. contributed equally to this work.

Correspondence should be addressed to Dr. Corey J. Keller, Stanford University, 401 Quarry Road, Palo Alto, CA 94305. E-mail: ckeller1@stanford.edu.

DOI:10.1523/JNEUROSCI.1088-17.2018

Copyright $\odot 2018$ the authors $\quad 0270-6474 / 18 / 385384-15 \$ 15.00 / 0$
} 
Following rTMS, excitability changes to this area can be measured with direct motor outputs such as the motor-evoked potential (MEP). Consistent with animal literature, high-frequency $(\geq 5 \mathrm{~Hz})$ rTMS to the motor cortex generally increase MEPs, whereas low-frequency $(1 \mathrm{~Hz}$ ) rTMS decrease MEPs (for review, see Fitzgerald et al., 2006). High-frequency motor cortex rTMS also modulates downstream regions functionally connected to the stimulation site (Siebner et al., 2000; Takano et al., 2004; Rounis et al., 2005).

Despite our understanding of plasticity in animal models and human motor cortex, little is known about the effects of repetitive stimulation in human nonmotor cortices. The conventional notion derived from animal slices and human motor cortex remains that high-frequency stimulation (1) consistently induces potentiation of cortical excitability (for review, see O'Reardon et al., 2006), and (2) affects all regions connected to the stimulation site (Funke and Benali, 2011; Pell et al., 2011; Tang et al., 2015). However, recent studies have shown heterogeneity in brain outcomes following repetitive stimulation of nonmotor areas. In particular, high-frequency prefrontal rTMS has been found to have opposing effects on reaction times during a working memory task (Rounis et al., 2006; Esslinger et al., 2014) and lead to highly variable changes in oscillatory power (Griskova et al., 2007; Barr et al., 2009; Woźniak-Kwaśniewska et al., 2014; for review, see Thut and Pascual-Leone, 2010). Furthermore, prefrontal rTMS alters task-based fMRI activity in regions connected with the stimulation site (Rounis et al., 2006), and may enhance (Halko et al., 2014; Wang et al., 2014) or have no effect on within-network connectivity (Eldaief et al., 2011). The heterogeneity observed in these studies are in part due to the inability (1) to localize cortical regions directly stimulated by noninvasive methods such as rTMS; or (2) to quantify focal downstream effects with fMRI or EEG, which have poor temporal and spatial resolution, respectively.

To study the effects of repetitive stimulation in humans with high spatiotemporal resolution, we performed corticocorticalevoked potential (CCEP) mapping before and after focused repetitive electrical stimulation. CCEP mapping applies single pulses of current measures causal local and remote electrophysiological responses with accurate localization of the stimulated region. CCEPs have been used to predict the onset of ictal events (David et al., 2008), examine the functional brain architecture (Keller et al., 2011, 2014b; David et al., 2013; Entz et al., 2014), and causally examine the frontoparietal (Matsumoto et al., 2012), hippocampal (Kubota et al., 2013), visual (Keller et al., 2017), and language (Koubeissi et al., 2012) networks.

Here, we hypothesized that repetitive electrical stimulation will induce excitability changes locally and in regions functionally connected to the stimulation site. In accordance, we demonstrated that using the CCEP, regions susceptible to brain changes could be accurately predicted with subjects' baseline anatomical and functional proximity profile. Further, we found that measuring excitability changes within the stimulation period itself can partially predict poststimulation effects and reveal unique cortical regions exhibiting transient neuronal changes. Taken together, these findings contribute to our understanding of the neurophysiological mechanisms underlying stimulationinduced brain changes.

\section{Materials and Methods}

Subjects. Eight patients with medically-intractable epilepsy at North Shore University Hospital (6 female, aged 40.8 years; range 21-57) participated in this study. Patient characteristics are described in Table 1. All patients
Table 1. Participant characteristics, electrode coverage, stimulation site, and parameters

\begin{tabular}{lllllll}
\hline ID & Age & Gender & Handedness & Seizure focus & Implant type & Stim location \\
\hline S1 & 43 & $\mathrm{~F}$ & $\mathrm{R}$ & Left parasagittal & Grid/strips & Left frontal \\
S2 & 50 & $\mathrm{~F}$ & $\mathrm{R}$ & Right 0FC/amygdala & Right sEEG & Right frontal \\
S3 & 48 & $\mathrm{~F}$ & $\mathrm{R}$ & Right mesial temporal & Bilateral sEEG & Right frontal \\
S4 & 46 & $\mathrm{M}$ & $\mathrm{R}$ & Right posterior temporal & Bilateral sEEG & Left frontal \\
S5 & 21 & $\mathrm{M}$ & $\mathrm{R}$ & Right mesial temporal & Grid/strips & Right motor \\
S6 & 57 & $\mathrm{~F}$ & $\mathrm{~L}$ & Left mesial temporal & Left sEEG & Left motor \\
S7 & 31 & $\mathrm{~F}$ & $\mathrm{R}$ & Right STG/mesial temporal & Right sEEG & Right motor \\
S8 & 30 & $\mathrm{~F}$ & $\mathrm{R}$ & Left mesial temporal & Grid/strips & Left temporal \\
\hline
\end{tabular}

sEEG, Stereotactic EEG; OFC, orbitofrontal cortex; STG, superior temporal gyrus.

provided informed consent as monitored by the local Institutional Review Board and in accordance with the ethical standards of the Declaration of Helsinki. The decision to implant, the electrode targets, and the duration of implantation were made entirely on clinical grounds without reference to this investigation. Patients were informed that participation in this study would not alter their clinical treatment, and that they could withdraw at any time without jeopardizing their clinical care.

Electrode registration. Our electrode registration method has been described in detail previously (Keller et al., 2011, 2013; Groppe et al., 2017). Briefly, to localize each electrode anatomically, subdural electrodes were identified on the postimplantation CT with BioImage suite (Duncan et al., 2004), and were coregistered first with the postimplantation structural MRI and subsequently with the preimplantation MRI to account for possible brain shift caused by electrode implantation and surgery (Mehta and Klein, 2010). Following coregistration, electrodes were snapped to the closest point on the reconstructed pial surface (Dale et al., 1999) of the preimplantation MRI (Dykstra et al., 2012). Intraoperative photographs were previously used to corroborate this registration method based on the identification of major anatomical features. Automated cortical parcellations were used to relate electrode data to anatomical regions (Fischl et al., 2004).

Selection of stimulation sites. In the first set of experiments, $10 \mathrm{~Hz}$ stimulation was applied to electrodes overlying prefrontal regions (S1-4; 2 left, 2 right). This experiment was performed to answer the question whether high-frequency stimulation of the prefrontal cortex leads to excitability changes in predictable brain regions. In the second set of experiments, $10 \mathrm{~Hz}$ stimulation was applied to motor (S5-7) and temporal (S8) cortex. This experiment was performed to determine whether results from prefrontal cortex stimulation are consistent with stimulation in other cortical regions, including the well studied motor cortex.

For the first set of experiments, the preferred stimulation site was within the dorsolateral prefrontal cortex (DLPFC) to mimic the targeting of rTMS for patients with depression (McClintock et al., 2018) and other neuropsychiatric disorders. As electrode placement was determined based on clinical criteria for seizure localization and not necessarily localized to the DLPFC, the following stepwise algorithm was implemented to select the stimulation electrodes. If electrodes were located in the DLPFC based on a preoperative MRI, then they were selected for target sites. If no electrodes were in the DLPFC, regions in the frontal cortex in close proximity to the DLPFC and not located in language regions (i.e., inferior frontal gyrus) were selected. In the second set of experiments, regions outside of prefrontal cortex were targeted to determine the generalizability of results. As most human plasticity studies are performed in motor cortex, the motor strip (as identified by functional stimulation mapping), when possible was the stimulation target (S5-S7). In one subject, the temporal cortex was the stimulation target because there were no electrodes in the prefrontal or motor cortex (S8).

Experimental design and statistical analysis. For each subject, we obtained prestimulation and poststimulation single pulse CCEPs to evaluate the change in cortical excitability as a result of repetitive stimulation. This was done by applying bipolar electrical stimulation (biphasic pulses at $100 \mu \mathrm{s} /$ phase) with a $1 \mathrm{~s}$ interstimulation interval (ISI). This ISI was chosen to allow voltage deflections to return to baseline after $\sim 500 \mathrm{~ms}$ and sufficient trials to be collected to establish a stable prestimulation CCEP baseline. A uniform random jitter $( \pm 200 \mathrm{~ms})$ was included in the 
Table 2. Participant characteristics, electrode coverage, stimulation site, and parameters

\begin{tabular}{|c|c|c|c|c|c|c|c|c|c|c|}
\hline ID & $\begin{array}{l}\text { Type of } \\
\text { stimulation, } \mathrm{Hz}\end{array}$ & $\begin{array}{l}\text { Lobe } \\
\text { stimulated }\end{array}$ & $\begin{array}{l}\text { MNI } \\
\text { coordinates }\end{array}$ & $\begin{array}{l}\text { Current, } \\
\mathrm{mA}\end{array}$ & $\begin{array}{l}\text { No. of recording } \\
\text { electrodes }\end{array}$ & $\begin{array}{l}\text { No. of } \\
\text { pre-stimulation } \\
\text { CCEPs }\end{array}$ & $\begin{array}{l}\text { No. of } \\
\text { post-stimulation } \\
\text { CCEPs }\end{array}$ & $\begin{array}{l}\text { Duration of } \\
\text { stimulation } \\
\text { (no. of pulses/train, } \\
\text { no. of cycles) }\end{array}$ & $\begin{array}{l}\text { Modulated } \\
\text { channels in early } \\
\text { time window, } \%\end{array}$ & $\begin{array}{l}\text { Modulated } \\
\text { channels in late } \\
\text { time window, \% }\end{array}$ \\
\hline S2 & 10,1 & Right prefrontal & $6,37,13$ & 4 & 110 & 200 & 399 & 50,60 & 36 & 1 \\
\hline S3 & 10 & Right prefrontal & $55,35,13$ & 4 & 219 & 358 & 997 & 50,60 & 6 & 4 \\
\hline S4 & 10 & Left prefrontal & $-51,13,4$ & 6 & 224 & 197 & 1161 & 50,60 & 10 & 6 \\
\hline S7 & 10 & Right motor & $57,-13,37$ & 1 & 199 & 147 & 343 & 50,60 & 0 & 2 \\
\hline S8 & 10 & Left temporal & $-35,27,-29$ & 7 & 190 & 230 & 860 & 50,60 & 49 & 30 \\
\hline
\end{tabular}

ISI to avoid potential entrainment effects. Stimulation current was chosen to match the lowest current that evoked movement during highfrequency $(50 \mathrm{~Hz})$ stimulation mapping of the motor cortex (i.e., $100 \%$ motor threshold). Up to 400 single pulses were applied to assess the baseline CCEP. To assess for excitability changes during the baseline CCEP assessment, we computed average CCEP amplitude change from the first half to the last half of the baseline CCEPs and found no significant differences (S1: $t=1.88, p=0.07 ; \mathrm{S} 2: t=1.23, p=0.22 ; \mathrm{S} 3: t=0.59$, $p=0.55 ;$ S $4: t=0.20, p=0.84$, two-sample $t$ test). Following repetitive stimulation between 300 and 1300 single pulses, as determined by experimental time allotted, were applied (biphasic: $1 \mathrm{~s}$ ISI $\pm 200 \mathrm{~ms}$ jitter) to capture the dynamic changes in the CCEP following stimulation. The number of pre and poststimulation CCEPs for each subject are shown in Table 2. The repetitive stimulation each subject received consisted of 12 min application of $10 \mathrm{~Hz}$ trains at $100 \%$ motor threshold. Each train was $5 \mathrm{~s}$ ( 50 pulses/train) followed by $10 \mathrm{~s}$ rest ( $15 \mathrm{~s}$ duty cycle), resulting in 60 total trains (3000 pulses) applied (Bakker et al., 2015). These parameters were chosen to closely mimic commonly used rTMS treatment paradigms (Rossi et al., 2009). In addition to the $10 \mathrm{~Hz}$ stimulation, $1 \mathrm{~Hz}$ stimulation was applied for Subject 2 with prestimulation and poststimulation CCEP assessment, following a washout period of at least 30 min. When applied in a sufficiently long manner, $1 \mathrm{~Hz}$ stimulation is thought to have opposing electrophysiological effects compared with $10 \mathrm{~Hz}$, in both healthy participants (for review, see Thut and PascualLeone, 2010) and in patients with depression (for review, see O'Reardon et al., 2006). The duration of $1 \mathrm{~Hz}$ stimulation was chosen to match the number of pulses applied in the $10 \mathrm{~Hz}$ stimulation. Electrophysiological data were analyzed off-line with custom scripts (MATLAB, MathWorks). Channels with high amplitude artifact $(\mathrm{SD}>500 \mu \mathrm{V})$ were excluded and remaining channels were notch filtered $(60 \mathrm{~Hz})$ to remove power line noise. CCEP quantification and statistical testing is described in the sections below.

CCEP quantification. CCEP was quantified as detailed previously (Matsumoto et al., 2004, 2007; Keller et al., 2011). Briefly, recording data from each channel were epoched -1000 to $1500 \mathrm{~ms}$ centered on the electrical pulse, and baseline corrected to -50 to $-10 \mathrm{~ms}$. Due to amplifier roll-offs, the initial $0-10 \mathrm{~ms}$ of the response is often contaminated with stimulation artifact and therefore is discarded from analysis. To increase signal-to-noise ratio, 10 consecutive CCEP waveforms were averaged before CCEP quantification. CCEPs exhibit an early sharp response ("A1"; 10-60 ms) and a later slow-wave ("A2"; 60-250 ms; Matsumoto et al., 2004, 2012; Keller et al., 2011, 2014b; Entz et al., 2014; Groppe et al., 2017). To quantify the CCEP, the area under the curve (AUC), peak-to-peak amplitude (pk-pk), peak amplitude, and the latency to peak were calculated for the early A1 $(10-60 \mathrm{~ms})$ and for the late A2 (60-250 ms) components of the CCEP. In computing latency, channels that have CCEP amplitude lower than $30 \mu \mathrm{V}$ were automatically excluded, as a clear peak was difficult to discern. We chose to use pk-pk for our primary analyses as peak amplitude often failed to capture the entire biphasic voltage deflection, and AUC was not a direct measure of voltage amplitude. Pk-pk amplitude was calculated by finding the difference between maximum and minimum voltage amplitudes within the timeframe of each CCEP component. We found strong correlation be- tween pre/poststimulation effect size calculated using the early A1 component between pk-pk amplitude and using other measures of the CCEP $\left(r_{\text {PKPK-PK }}=0.619, p<0.001, r_{\text {PKPK-AUC }}=0.554, p<0.001\right)$. We also assessed the polarity of CCEP, either positive or negative, to evaluate its relationship (if any) with potentiation or depression effects. Polarity of the CCEP was determined based on the direction of largest voltage deflection within the time period of interest.

Quantification of CCEP modulation. To determine which regions undergo significant excitability change following the stimulation period, two-sample $t$ test was performed comparing the pk-pk amplitude distribution between the prestimulation CCEPs and poststimulation CCEPs for each channel. For each subject, the set of $p$ values were adjusted to a false discovery rate (FDR) of 5\% (Yekutieli and Benjamini, 1999). Adjusted $p$ values were converted to $z$-scores using the normal inverse cumulative distribution function. Channels with adjusted values below $q=$ 0.05 ( $5 \%$ FDR) were considered to have been modulated by repetitive stimulation. Finally, to quantify the magnitude of change following stimulation, Cohen's $d$ (Cohen, 1998) effect size was calculated based on the poststimulation pk-pk amplitude relative to the prestimulation baseline. The equation for Cohen's $d$ is as follows:

$$
d_{s}=\frac{\overline{X_{1}}-\overline{X_{2}}}{\sqrt{\frac{\left(n_{1}-1\right) S D_{1}^{2}+\left(n_{2}-1\right) S D_{2}^{2}}{n_{1}+n_{2}-2}}} .
$$

Where $\bar{X}_{1}$ and $\bar{X}_{2}$ are means of tested samples. The denominator is the pooled standard deviation (SD).

Quantification of prestimulation cortical characteristics. Prestimulation cortical characteristics were quantified to determine features that predict cortical regions susceptible to plasticity following repetitive stimulation. For each channel, we calculated prestimulation mean CCEP amplitude, mean latency, and Euclidean distance between the stimulation site and the channel of interest. For S1, S5, and S8, whose recording channels were surface electrodes, we also computed geodesic distance from the stimulation site to the channel of interest. Geodesic distances and Euclidean distances were highly correlated in the three subjects $\left(R_{\mathrm{S} 1}^{2}=0.90, R_{\mathrm{S} 5}^{2}=\right.$ $\left.0.84, R_{\mathrm{S} 7}^{2}=0.92\right)$. Although we presented results using exclusively Euclidean distance in this study, secondary analysis using geodesic distance in these three patients produced similar findings and did not change our interpretation of the results.

Comparison of prestimulation features with poststimulation CCEP changes. The prestimulation amplitude, latency, and, distance to stimulation site were first compared between modulated and nonmodulated channels. Bar graphs are used to show the spread of the raw data, including the $95 \%$ confidence interval and the SD (see Fig. 3). Mann-Whitney $U$ test was used to test for differences between modulated and nonmodulated channels for each subject. We performed group analysis by aggregating all single-subject data, normalizing for between-subject variations (Cousineau, 2005), and testing for differences between modulated and nonmodulated channels using two-sample $t$ test. On group analysis, we found that distance was highly collinear with prestimulation amplitude and latency $\left(r_{\text {DistanCE-AMPLITUde }}=-0.449, p<0.001\right.$, 
$r_{\text {DISTANCE-LATENCY }}=0.700, p<0.001$ ), so distance-constrained analysis was performed. We repeated single-subject and group analysis using only channels between 10 and $50 \mathrm{~mm}$ of the stimulation site. Channels within $10 \mathrm{~mm}$ of the stimulation site were prone to volume conduction; conversely, channels further than $50 \mathrm{~mm}$ away were not modulated in sufficient quantities to allow for statistical testing. Distance restraints tested in this analysis included electrodes within $10-25,10-30,10-35,10-40$, $10-50$, and $20-40 \mathrm{~mm}$ of the stimulation site. Results for $10-40 \mathrm{~mm}$ are shown as this grouping contained the most balanced ratio of modulated to nonmodulated channels (46:151). Analysis using the other distance restraints yielded similar findings.

Support vector machine and multiple linear regression. Prediction of modulated cortical regions before application of repetitive stimulation would be clinically useful. Therefore, we performed binary classification and regression analyses to address this important question. To determine whether prestimulation amplitude, latency, and distance predicted the magnitude of poststimulation excitability changes, we performed stepwise multiple linear regression. The predictor variables were log transformed to linearize against effect size. Prestimulation variables were entered into the regression model in the following order: distance, amplitude, and latency. Distance is used as the primary predictor as it is a more clinically accessible value. Regression models were built for each subject and for the aggregate data.

In addition to linear regression, we assessed whether prestimulation variables predicted modulated channels using support vector machine (SVM). This approach classifies data by creating a hyperplane that separates data with support vectors being data closest to the separating hyperplane (Cortes and Vapnik, 1995). Here, SVM was used to classify modulated channels from nonmodulated channels using prestimulation amplitude, latency, and distance as predictors. For the classification process, a random sample of half of the data was used to train the classifier and the other half was used as test data. Receiver operating characteristic (ROC) curves were generated from sensitivity/specificity calculations to visualize the SVM classification performance. We estimated the prognostic ability of our SVM model to discriminate between modulated and nonmodulated channels by determining the AUC of the ROC curve. To adjust for overfitting, we used bootstrap sampling to control for overly optimistic discriminability. One-thousand random bootstrap samples were used to calculate the mean and 95\% confidence interval of the AUC of the model. Additionally, we calculated accuracy, which is defined as the proportion of all channels correctly classified. Sensitivity ("hit rate") was computed as the proportion of modulated channels correctly classified; specificity ("correct rejection rate") was computed as the proportion of nonmodulated channels correctly classified. The optimal operating point of the ROC curve was determined by finding the slope, $S$, using:

$$
S=\frac{\operatorname{Cost}(P \mid N)-\operatorname{Cost}(N \mid N)}{\operatorname{Cost}(N \mid P)-\operatorname{Cost}(P \mid P)} * \frac{N}{P}
$$

where $\operatorname{Cost}(N \mid P)$ is the cost of a false-negative. $\operatorname{Cost}(P \mid N)$ is the cost of a false-positive. $P=$ true positive + false-negative and $N=$ true negative + false-positive. The optimal operating point is the intersection between the line with slope $S, y$-intercept of 1 , and the ROC curve. A random predictor was constructed as a set of uniformly distributed random numbers to serve as a control.

Quantification of the intrastimulation potential and dynamics. During stimulation, robust evoked potentials were observed during the 10-60 ms timeframe following each pulse in a train. We termed this response the intra-train evoked potential (IEP). To quantify the IEP, recording data from the first pulse in each stimulation train was epoched from -100 to $100 \mathrm{~ms}$ centered on the electrical pulse and baseline corrected to -50 to $-10 \mathrm{~ms}$ (the same baseline used in CCEP calculation). We limited the analysis to only the first pulse in each stimulation train, as it best approximates the evoked potential arising from rest. Three consecutive train pulses were averaged to improve signal-to-noise. IEP amplitude was quantified in the same manner as describe above for CCEP amplitude.

In contrast to pre/post-CCEP measurements, IEP represents excitability changes during stimulation. IEP changes during stimulation were quantified using two methods: (1) Pearson's correlation coefficient $(r)$ between the IEP pk-pk amplitude and train number, and (2) the IEP effect size between the first third and final third of the stimulation trains. Two-sample $t$ test was used to compare IEPs in the first third and the final third of the stimulation trains.

\section{Results}

Repetitive stimulation in the prefrontal cortex induces excitability changes in humans

First, we asked whether there are measurable cortical excitability changes resulting from the application of repetitive cortical stimulation by examining the early A1 (10-60 ms) component of the CCEP. This early component was chosen to capture more direct connections with the stimulation site. Single-pulse stimulation to the prefrontal cortex generated robust CCEPs quantifiable at the single-trial level (Fig. 1 $A, B$ ), which were observed at both local and remote cortical regions (Fig. $2 B$, left). We found that $10 \mathrm{~Hz}$ stimulation elicited both potentiation (Fig. $1 C-F$ ) and depression (Fig. 1G-J) in CCEP amplitude that persisted after completion of the stimulation protocol. In most cases, the CCEP amplitude returned close to baseline after $\sim 10 \mathrm{~min}$ (Fig. $1 H-J$, Subject 1 ; representative electrode; unpaired $t$ test, $t_{\text {pre,early }}=14.454, t_{\text {pre,late }}=$ 6.067, $p<0.0001$ ); however, at times amplitude changes persisted (Fig. 1D-F, Subject 4; unpaired $t$ test, $t_{\text {pre,early }}=7.39, t_{\text {pre,late }}=7.70$, $p<0.0001)$. Across the four subjects undergoing prefrontal stimulation, statistically significant CCEP modulation was observed in at least one cortical region following $10 \mathrm{~Hz}$ stimulation (Fig. $2 A, B) .10 \mathrm{~Hz}$ stimulation modulated $11 \%$ of all cortical regions probed (73 modulated/661 total regions), of which potentiation occurred in $51 \%$ of modulated regions and depression in $49 \%$ of regions (Fig. $2 B, D$ ). Of the regions modulated, 45\% demonstrated sustained ( $>10 \mathrm{~min}$ ) excitability changes (Fig. $2 \mathrm{~B}$, right, $C)$. No regions demonstrated late modulation that did not show early modulation (Fig. 2C). Of regions modulated, 94\% were short-range $(<3 \mathrm{~cm}$ from stimulation site) and $6 \%$ long-range $(>3 \mathrm{~cm}$ from stimulation site; Fig. 2E). Qualitatively, similar prestimulation CCEP amplitude and effect size maps were observed (Fig. 2B, left), which are quantified further in subsequent sections.

\section{Modulated regions are anatomically and functionally closer to the stimulation site}

What are the unique features of modulated regions that make it susceptible to changes following repetitive stimulation? To address this question, we next explored the relationship between observed excitability changes and baseline connectivity profile at each channel. For each channel we computed the distance from stimulation site, prestimulation CCEP amplitude, and prestimulation CCEP latency to peak (Fig. 3). Single-pulse stimulation was found to elicit stronger CCEP amplitude at modulated regions compared with nonmodulated regions (Fig. $3 A$; left: $F_{\text {(subject:3,653) }}=$ 37.5, $p<0.0001 ; F_{\text {(modulation:1,653) }}=231.9, p<0.0001$; right: group mean amplitude $\mathrm{mod}_{\mathrm{m}}=210 \mu \mathrm{V}$, amplitude non-mod $=52$ $\mu \mathrm{V}, t=4.2, p=0.0059$; unpaired $t$ test), and post hoc testing demonstrated this effect on a single-subject basis (Fig. 3A; MannWhitney $U$ test; $p<0.001)$. Additionally, modulated regions exhibited shorter CCEP latency compared with nonmodulated regions (Fig. 3B; left: $F_{(\text {subject:3,534) }}=10.7, \mathrm{p}<0.0001 ; F_{(\text {modulation:1,534) }}=$ 93.2, $p<0.0001$; right: group mean latency ${ }_{\bmod }=22 \mathrm{~ms}$, latency $_{\text {non-mod }}=34 \mathrm{~ms}, t=4.45, p=0.0043$; unpaired $t$ test). This effect was significant in three of four subjects (MannWhitney $U$ test, $p<0.05$ ). Finally, modulated regions were $l o-$ cated closer to the stimulation site compared with nonmodulated regions (Fig. 3C; left: two-factor ANOVA, $F_{(\text {subject:3,640) }}=20.3$, 
A

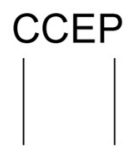

Pre-stim CCEP (5 min)
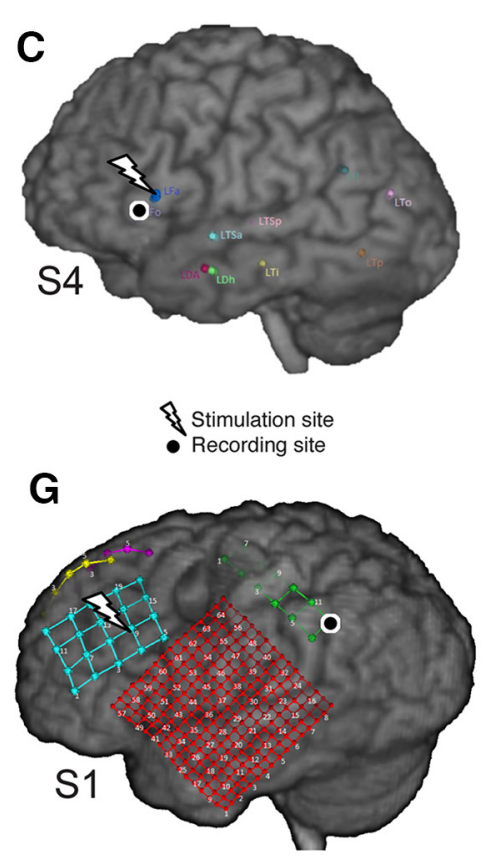

$10 \mathrm{~Hz}$

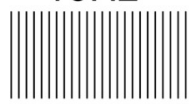
Stim (15 min)
B

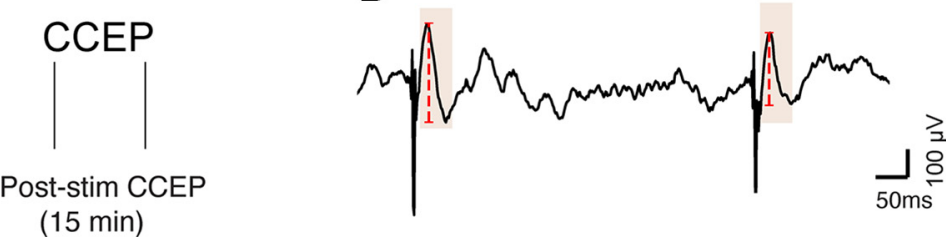

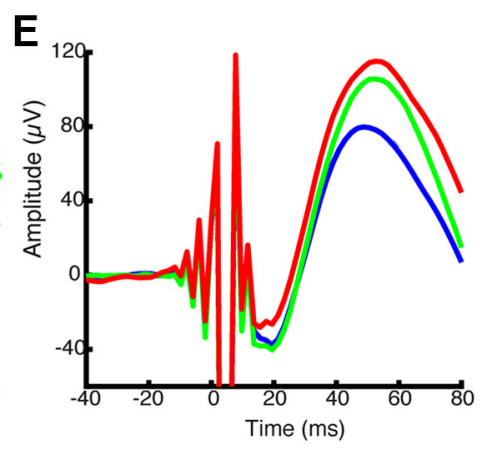

I

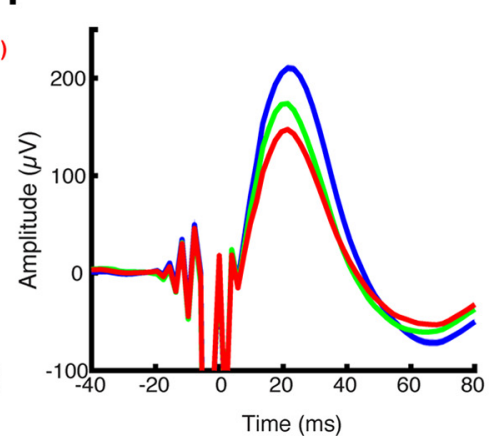

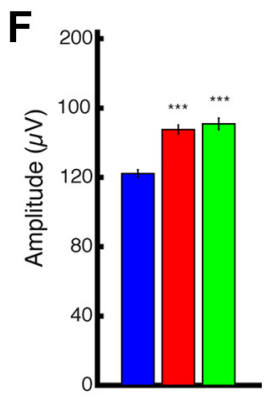

H

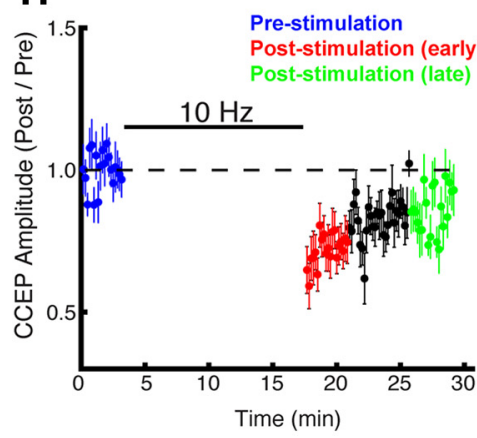

J

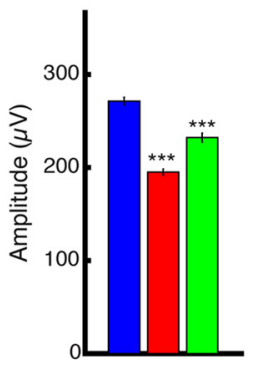

Figure 1. Repetitive stimulation elicited changes in the cortico-cortical evoked potentials (CCEP) that outlasted the stimulation by at least 5 min. $A$, Schematic showing experimental setup. Prestimulation and poststimulation CCEPs are used to probe cortical excitability and connectivity changes from the stimulation protocol. $\boldsymbol{B}$, Example of two consecutive CCEPs. Shaded region indicates time window used to quantify peak-to-peak amplitude represented by vertical red line. Traces are taken from recording site in C. C, Reconstructed preoperative MRI coregistered with postoperative CT of subdural electrodes located on the cortical surface. Lightning bolt denotes stimulation site, whereas circle represents exemplar recording site. D, Scatterplot of CCEP amplitude before and after $10 \mathrm{~Hz}$ stimulation at recording electrode in C. Amplitude is expressed as the ratio of poststimulation versus prestimulation. Each data point ( \pm SE bars) represents 10 consecutive CCEPs. Blue regions represent prestimulation time periods, whereas red and green regions represent the early $(0-3 \mathrm{~min})$ and late $(7-10 \mathrm{~min})$ poststimulation time periods, respectively. $E$, Mean CCEP waveforms for each time period illustrated in $\boldsymbol{D}$. Shaded regions represent SE ( $n=100$ trials/mean CCEP). $\boldsymbol{F}$, Quantification of CCEPs following $10 \mathrm{~Hz}$ stimulation. Poststimulation distributions (red and green bars) are compared with prestimulation (blue) data. Wilcoxon rank sum test, ${ }^{* * *} p<0.001$ after correction for multiple comparisons. $\mathbf{G}-\boldsymbol{J}$, Same as $\mathbf{C}-\boldsymbol{F}$ but for another subject demonstrating effect from stimulation. Note the decrease in CCEP amplitude following $10 \mathrm{~Hz}$ stimulation at this recording site remote to stimulation site.

$p<0.0001 ; F_{(\text {modulation:1,640) }}=154.2, p<0.0001$; right: group mean dist $\mathrm{mod}_{\text {mod }}=28 \mathrm{~mm}$, dist $\mathrm{non}$-mod $=63 \mathrm{~mm}, t=6.8, p=$ 0.0005; unpaired $t$ test). This was also true at the single-subject level (Fig. 3C; Mann-Whitney $U$ test; $p<0.001$ ).

As distance to stimulation site was highly collinear with prestimulation CCEP amplitude and latency across channels, we compared modulated and nonmodulated channels after constraining channels within a given distance range from the stimulation site (see Materials and Methods). For each of the constrained distance ranges analyzed, stronger CCEP amplitudes were observed in modulated regions compared with nonmodulated regions (Fig. 3D; two-way ANOVA; $F_{\text {(modulation effect:1,228) } 1-5 \mathrm{~cm}}=52.9, F_{(1,183) 1-4 \mathrm{~cm}}=48.2$, $F_{(1,82) 1-3 \mathrm{~cm}}=15, F_{(1,57) 1-2.5 \mathrm{~cm}}=13.5, F_{(1,150) 2-4 \mathrm{~cm}}=4.3$; all $p<$ 0.01 ; group unpaired $t$ test $\left.t_{(1-4 \mathrm{~cm})}=3.95, p_{(1-4 \mathrm{~cm})}=0.007\right)$. However, no difference in latency was observed in modulated regions when controlling for distance (Fig. 3E, two-way ANOVA; $F_{(\text {modulation effect:1,225) } 1-5 \mathrm{~cm}}=2.78, p=0.09 ; F_{(1,184) 1-4 \mathrm{~cm}}=2.3, p=$ $0.12 ; F_{(1,86) 1-3 \mathrm{~cm}}=0.3, p=0.8 ; F_{(1,61) 1-2.5 \mathrm{~cm}}=5.9, p=0.017$; $F_{(1,147) 2-4 \mathrm{~cm}}=0.03, p=0.8$; group paired $t$ test $t_{(1-4 \mathrm{~cm})}=0.057$, $\left.p_{(1-4 \mathrm{~cm})}=0.95\right)$.

\section{Modulated regions can be predicted by baseline} connectivity profiles

To assess whether prestimulation connectivity profile can predict the magnitude of excitability changes across different regions of the brain, we performed a multivariate linear regression analyses. First, prestimulation variables (natural-logarithm of amplitude, latency and 1/distance) were linearized against effect size on group analysis $\left(r_{\text {amplitude-cohenD }}=0.427, p<0.001 ; r_{\text {latency-cohenD }}=\right.$ $-0.4511, p<0.001 ; r_{\text {distance-cohenD }}=0.510$, all $\left.p<0.001\right)$. Similar linear relationships were observed in each subject (range: $r_{\text {amplitude-cohenD }}=0.212-0.528, r_{\text {latency-cohenD }}=-0.336$ to $-0.555, r_{\text {distance-cohenD }}=0.582-0.622$, all $\left.\mathrm{p}<0.05\right)$. Prestimulation variables were entered in the model in a stepwise manner to predict the effect size on a given channel following repetitive stimulation (Table 3). Channel distance to the stimulation site was used as the baseline predictor upon which prestimulation CCEP amplitude and latency were subsequently added. The rationale for this was that anatomical proximity is a readily accessible parameter whereas CCEP amplitude and latency are not. Thus we asked whether these functional metrics provided further 
A
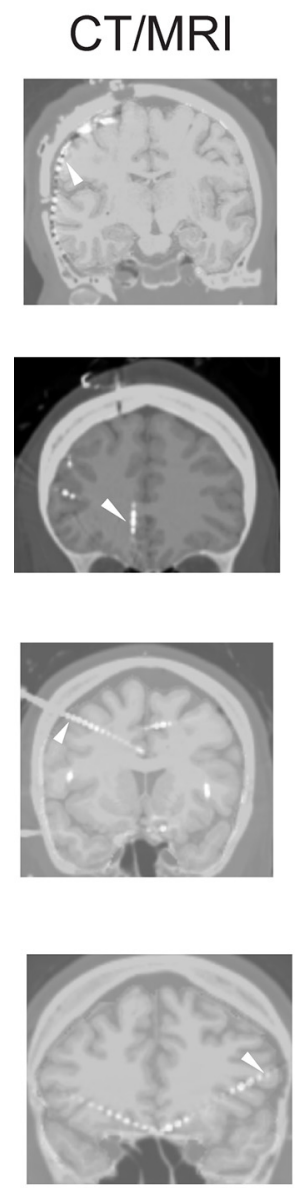

B
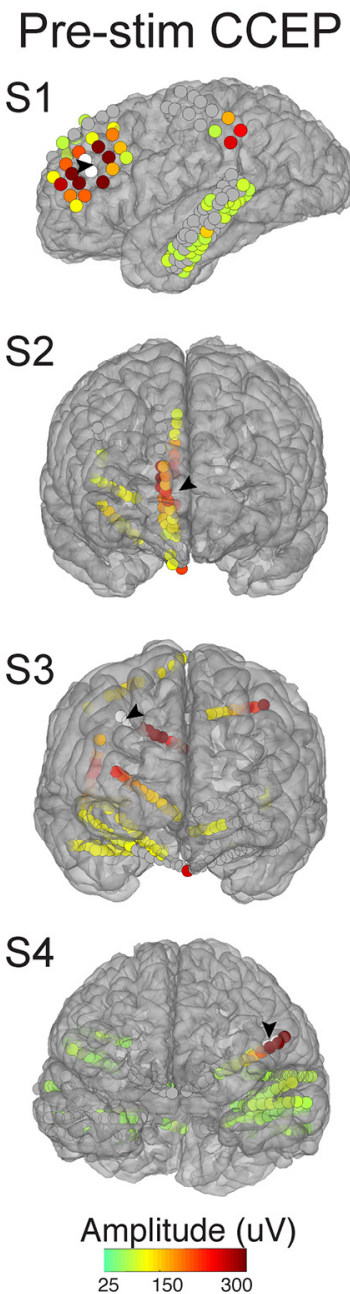
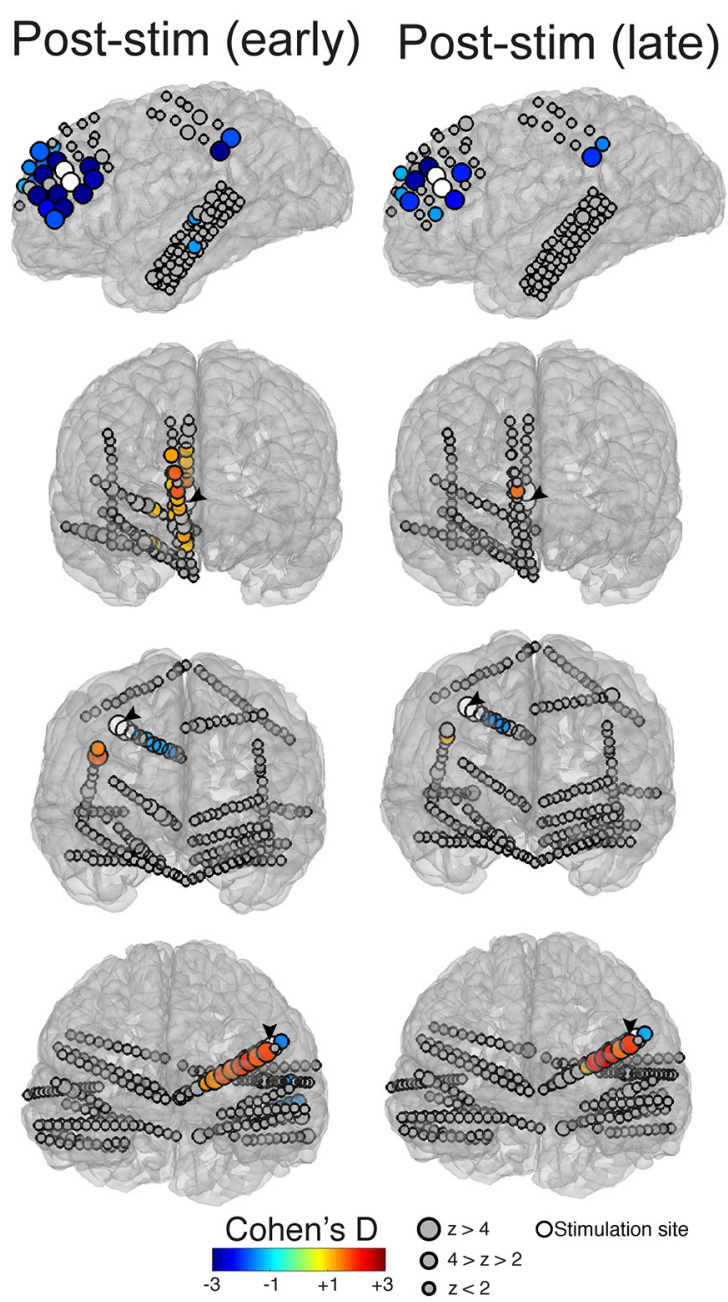

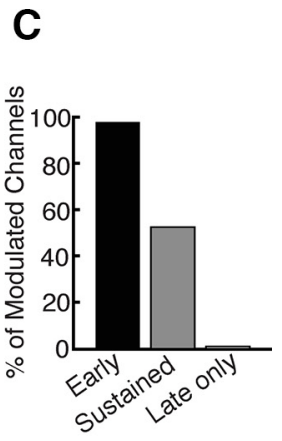

D
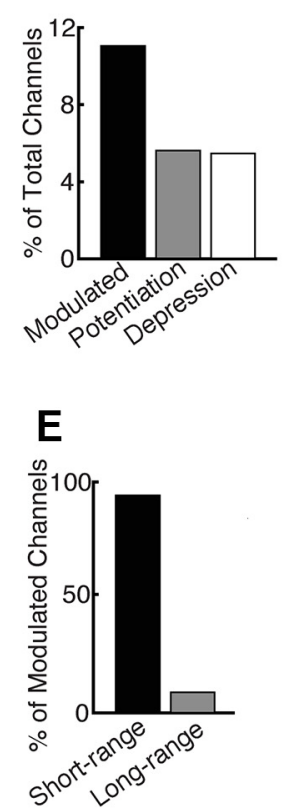

Figure 2. Cortical excitability changes outlasting stimulation was observed in all subjects and differed with respect to the direction of change. $\boldsymbol{A}$, Preoperative MRI coregistered with postoperative (T showing intracranial electrodes and stimulation site (arrow). B, Single-subject brain plots represent prestimulation CCEP and poststimulation (early and late) change in CCEP. Colors of each electrode represent regions that demonstrated positive (warm colors) or negative (colder colors) CCEP effect size due to stimulation. Brain plots were thresholded based on 5\% FDR significance level. Electrode size represents z-score relative to a normal distribution (see key). $\boldsymbol{C}-\boldsymbol{E}$, Group summary quantifying excitability change (C) duration, (D) direction, and $(\boldsymbol{E})$ the effect of distance.

predictive power on top of using distance as a predictor. For subject and group analyses, the final model combining all three features was significantly more predictive compared with the distanceonly model (Table 3). Distance alone as a predictor did account for at least $70 \%$ of the final $R^{2}$ value in each model. It is worth noting that some subjects (S1, S2) demonstrated a $>25 \%$ improvement in predictive power with the addition of functional measurements (CCEP amplitude, latency), whereas others (S3, S4) did not. Together, adding functional metrics (amplitude and latency) to distance measurements can further improve the explanatory power of our models to predict the strength of plasticity following stimulation.

Next, we constructed a binary classifier to see whether prestimulation variables can be used to correctly identify modulated channels. We obtained model discriminability of $>85 \%$ in all subjects undergoing prefrontal cortex stimulation $[\mathrm{S} 1(95 \% \mathrm{CI})=87$ (74-94), S2 = 85 (69-93), S3 = 99 (93-100), S4 = 87 (71-96)]. Sensitivity ranged from 71 to $90 \%$, specificity from 85 to $95 \%$ (Table 4), and accuracy from 80 to $95 \%$ (Fig. $4 B$ ). The same analysis was performed after pooling individual data into a single dataset. The group model [AUC $=89(83-92)$, Accuracy $=80 \%$ ] performed similarly to individual subject models. Using the group ROC curve, we outlined four cutoffs representing different sensitivity and specificity (Table 5), which showed that increasing model sensitivity corresponded with higher distance threshold, lower amplitude threshold, and longer latency threshold.

\section{Effects of stimulation frequency on the direction of}

excitability change

Time constraints limited the ability to stimulate at multiple frequencies for all subjects, but in one subject (S2), $1 \mathrm{~Hz}$ stimulation was performed after a 30 min washout period from time of the 10 $\mathrm{Hz}$ stimulation. Figure $5 \mathrm{~A}$ illustrates the differential frequencydependent neuromodulatory effects in this subject. $10 \mathrm{~Hz}$ stimulation resulted overall in potentiation at a majority of electrodes, whereas $1 \mathrm{~Hz}$ stimulation elicited suppression. Mean effect size following $10 \mathrm{~Hz}$ stimulation was significantly higher than following $1 \mathrm{~Hz}$ stimulation (Fig. $5 B ; n=141, d_{10 \mathrm{~Hz}}=0.62, d_{1 \mathrm{~Hz}}=-0.03$, $t_{(108)}=8.3, p<0.001$, paired $t$ test). Across all electrodes, a significant negative correlation was observed between effect sizes of 10 and $1 \mathrm{~Hz}$ stimulation (Fig. $5 C$; $r=-0.34, p<0.001$ ). 


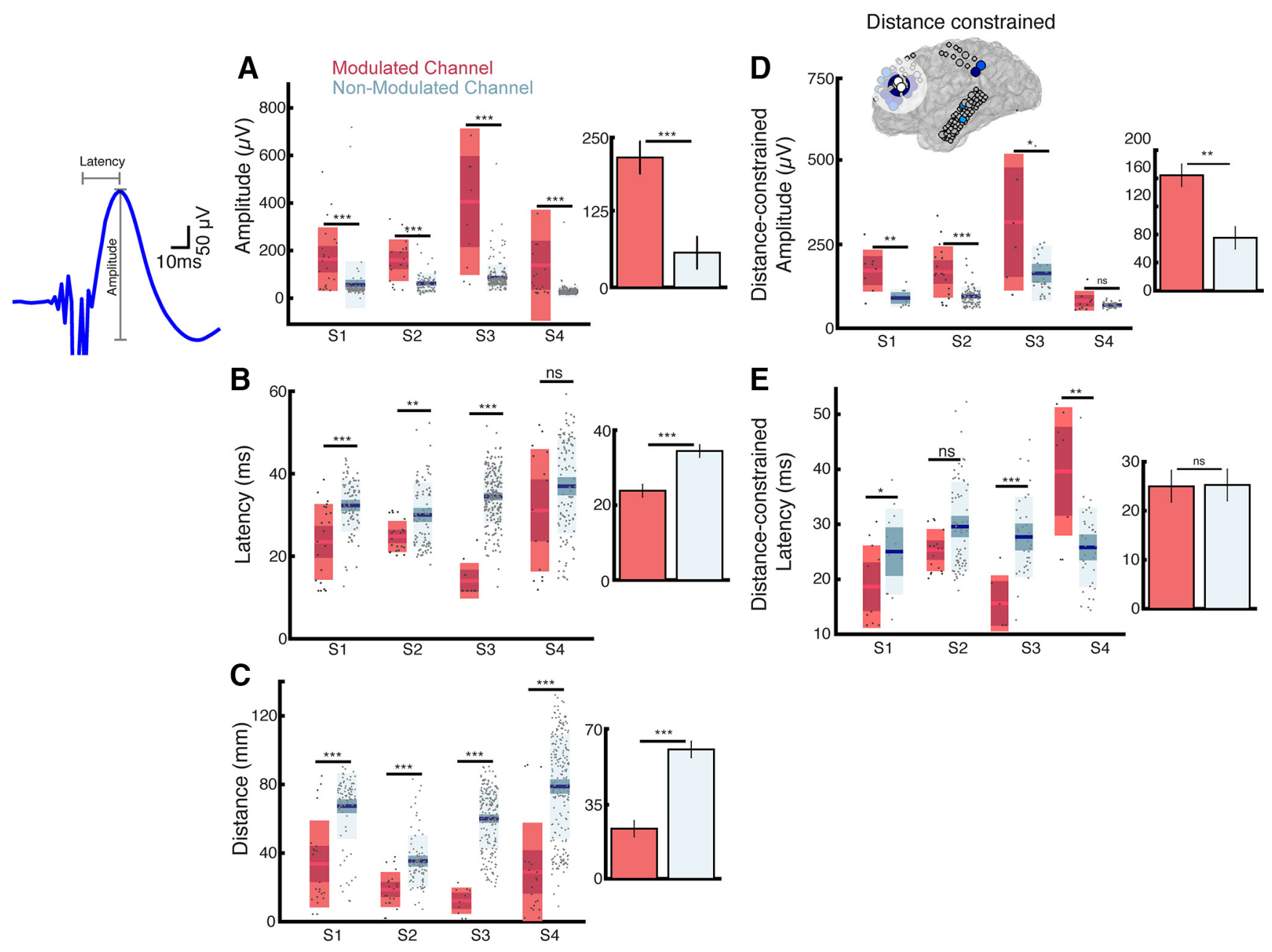

Figure 3. Modulated regions were anatomically and functionally closer to stimulation site. $\boldsymbol{A}-\boldsymbol{C}$, Boxplots showing the single-subject relationship of modulation and prestimulation $(\boldsymbol{A})$ amplitude, $(\boldsymbol{B})$ latency, and $(\boldsymbol{C})$ distance. Left, Example of how amplitude and latency were quantified. Right, Group results derived from single-subject analysis. $\boldsymbol{D}, \boldsymbol{E}$, Distance-controlled relationship of modulation and amplitude and latency. Top, Example of effect size with transparent outline of distance-constrained analysis. Note that amplitude was stronger in modulated regions after correcting for distance, but latency no longer demonstrates a statistical effect. ${ }^{*} p<0.05,{ }^{* *} p<0.01$, ${ }^{* * *} p<0.001$, Mann-Whitney $U$ test.

Table 3. Multiple linear regression analysis for variables predicting poststimulation effect size

\begin{tabular}{|c|c|c|c|c|c|c|c|c|c|c|c|c|c|c|}
\hline \multirow[b]{2}{*}{ Predictor } & \multicolumn{2}{|c|}{$\begin{array}{l}\text { S1 prefrontal } \\
(N=108)\end{array}$} & \multicolumn{2}{|c|}{$\begin{array}{l}\text { S2 prefrontal } \\
(N=109)\end{array}$} & \multicolumn{2}{|c|}{$\begin{array}{l}\text { S3 prefrontal } \\
(N=208)\end{array}$} & \multicolumn{2}{|c|}{$\begin{array}{l}\text { S4 prefrontal } \\
(N=223)\end{array}$} & \multicolumn{2}{|c|}{$\begin{array}{l}\text { S1-S4 prefrontal } \\
(N=648)\end{array}$} & \multicolumn{2}{|c|}{$\begin{array}{l}\text { S5-S7 motor } \\
(N=513)\end{array}$} & \multicolumn{2}{|c|}{$\begin{array}{l}\text { S8 temporal } \\
(N=190)\end{array}$} \\
\hline & $\beta$ & $\operatorname{SE}(\beta)$ & $\beta$ & $\operatorname{SE}(\beta)$ & $\beta$ & $\operatorname{SE}(\beta)$ & $\beta$ & $\operatorname{SE}(\beta)$ & $\beta$ & $\operatorname{SE}(\beta)$ & $\beta$ & $\operatorname{SE}(\beta)$ & $\beta$ & $\operatorname{SE}(\beta)$ \\
\hline Distance & 0.245 & 0.179 & 0.128 & 0.092 & 0.226 & 0.057 & 0.456 & 0.061 & 0.279 & 0.045 & 0.195 & 0.040 & 0.133 & 0.152 \\
\hline Amplitude & 0.669 & 0.139 & 0.151 & 0.084 & 0.067 & 0.050 & 0.123 & 0.061 & 0.105 & 0.035 & 0.167 & 0.032 & 0.853 & 0.092 \\
\hline Latency & -0.383 & 0.358 & -0.374 & 0.180 & -0.248 & 0.109 & 0.359 & 0.104 & -0.258 & 0.093 & 0.150 & 0.069 & 0.781 & 0.265 \\
\hline \multicolumn{15}{|l|}{$R^{2}$ for each stepwise model } \\
\hline Distance & \multirow{3}{*}{\multicolumn{2}{|c|}{$\begin{array}{l}0.339 \\
0.480\left(26.0^{* * * *}\right) \\
0.486(1.2)\end{array}$}} & \multirow{2}{*}{\multicolumn{2}{|c|}{$\begin{array}{l}0.185 \\
0.235\left(6.8^{* *}\right)\end{array}$}} & \multicolumn{2}{|l|}{0.374} & \multicolumn{2}{|l|}{0.387} & \multicolumn{2}{|l|}{0.260} & \multicolumn{2}{|c|}{0.135} & \multicolumn{2}{|l|}{0.107} \\
\hline+ Amplitude $\left(\chi^{2}\right.$ for $\left.\Delta\right)$ & & & & & $0.386\left(4.3^{*}\right.$ & & 0.398 & & $0.277(14$ & & 0.173( & $\left.6^{* * *}\right)$ & 0.471( & $\left.3.8^{* * *}\right)$ \\
\hline + Latency $\left(\chi^{2}\right.$ for $\left.\Delta\right)$ & & & \multirow{2}{*}{\multicolumn{2}{|c|}{$\begin{array}{l}0.265\left(4.4^{*}\right) \\
12.6^{* * * *}\end{array}$}} & \multicolumn{2}{|c|}{$0.402\left(5.3^{*}\right)$} & \multicolumn{2}{|c|}{$0.430\left(11.9^{* * *}\right)$} & \multicolumn{2}{|c|}{$0.285\left(7.8^{* *}\right)$} & \multicolumn{2}{|c|}{$\begin{array}{l}0.179\left(4.8^{*}\right) \\
373^{* * *}\end{array}$} & \multicolumn{2}{|c|}{$0.492\left(8.7^{* *}\right)$} \\
\hline F for final model & \multicolumn{2}{|c|}{$\begin{array}{l}0.486(1.2) \\
32.8^{* * *}\end{array}$} & & & $45.6^{* * *}$ & & $55.0^{* *}$ & & $85.8^{* * *}$ & & $37.3^{* * *}$ & & $61.1^{* *}$ & \\
\hline
\end{tabular}

All predictors are log-transformed to base e.1/distance is used.

${ }^{*} p<0.05,{ }^{* *} p<0.01,{ }^{* * *} p<0.001$.

Repetitive stimulation modulates the early and late components of the CCEP

The CCEP is a complex waveform consisting of multiple voltage deflections lasting up to $500 \mathrm{~ms}$ (Fig. 6A). Although the early A1 $(<60 \mathrm{~ms})$ CCEP component reflects more direct corticocortical connections and has been evaluated thus far, whether the later A2 (>60 ms) CCEP component captures similar or different dynamics is unclear. To evaluate the slow A2 CCEP potential (Matsumoto et al., 2004; David et al., 2013; Keller et al., 2014a), we quantified peak amplitude in the 60-250 ms timeframe and computed the pre/poststimulation effect sizes. We observed modulatory effects in the A2 CCEP component, with a smaller proportion (but nonsignificant) of regions modulated compared with the A1 CCEP component (Fig. $6 B, C$; regions modulated $($ mean $\pm \mathrm{SD}) ; \mathrm{A} 1=19.1 \pm 6.8 \% ; \mathrm{A} 2=$ $5.6 \pm 3.1 \% ; t_{(3)}=1.76, p=0.17$; paired $t$ test). Excitability changes in both A1 and A2 CCEP components were observed in overlapping cortical regions in S1 and S4 (Fig. 6B). S2 did not demonstrate significant change in the A2 CCEP component 
Table 4. Classification sensitivity and specificity at optimal predictor thresholds

\begin{tabular}{|c|c|c|c|c|c|}
\hline & Sensitivity & Specificity & $\begin{array}{l}\text { Distance } \\
\text { threshold, } \\
\mathrm{mm}\end{array}$ & $\begin{array}{l}\text { Amplitude } \\
\text { threshold, } \\
\mu V\end{array}$ & $\begin{array}{l}\text { Latency } \\
\text { threshold, } \\
\text { ms }\end{array}$ \\
\hline \multicolumn{6}{|c|}{ Model: distance + amplitude + latency } \\
\hline S1 prefrontal & 0.84 & 0.85 & 82 & 56 & 31 \\
\hline S2 prefrontal & 0.71 & 0.90 & 20 & 106 & 23 \\
\hline S3 prefrontal & 0.90 & 0.95 & 24 & 106 & 27 \\
\hline S4 prefrontal & 0.76 & 0.95 & 31 & 43 & 23 \\
\hline S1-S4 Prefrontal & 0.60 & 0.95 & 29 & 566 & 13 \\
\hline S5-S7 Motor & 0.67 & 0.95 & 40 & 68 & 42 \\
\hline S8 Temporal & 0.54 & 0.90 & 47 & 92 & 58 \\
\hline
\end{tabular}

whereas S3 exhibited excitability change in the A2 CCEP component at a new cortical area (across a slightly distributed set of cortical areas; intrasubject mean $R_{\mathrm{A} 1, \mathrm{~A} 2}=0.32$ ). In summary, changes in excitability can be observed in the late component of the CCEP and appear to occur in a lower proportion of the cortex than the early CCEP component.

\section{Intrastimulation dynamics partially reflect poststimulation excitability changes}

To further understand the dynamics of excitability changes, we quantified the voltage deflections evoked by the first pulse within a stimulation train. We found that IEPs can be observed and quantified on a single-trial level (Fig. $7 A$ ). At an exemplar site (Fig. $7 A, B$; the same site in Fig. $1 G-J$ ), IEPs decreased linearly over time as the number of stimulation trains increased. As expected, we observed that the amplitude of the last IEP in the stimulation period is approximately equal to the amplitude of the first poststimulation CCEP. To visualize the IEP waveform, we divided the stimulation period into three equal segments and plotted the average voltage deflections (Fig. $7 B$ ). The IEP occurs mostly within 20-50 ms, with amplitude peaking $\sim 25 \mathrm{~ms}$ (Fig. 7C). Over time during the stimulation period, we observed a reduction in IEP amplitude (Fig. 7D). To examine how intrastimulation dynamics correlate with pre/post testing, we plotted IEP and CCEP effect sizes on brain surfaces (Fig. 7E). S1 and S3 showed similar direction and spatial localization of channels undergoing IEP or CCEP change, whereas this was not observed in S2 and S4. Specifically, S2 showed IEP amplitude suppression in cortical regions distinct from where CCEP amplitude potentiation was observed on pre/post testing. Similarly, for S4, IEP changes occurred contralateral to where pre/post dynamics were observed. These relationships are further quantified in scatterplots, which showed positive correlation between IEP and CCEP effect sizes in S1 and S3 but no significant correlation in S2 and S4 (Fig. 7E). Furthermore, we showed that on average, channels with potentiation of IEP amplitude corresponded with potentiation of CCEP amplitude (Fig. 7F; two-factor ANOVA, $F_{\text {(subject:3,653) }}=64.9, p<$ $0.0001 ; F_{(\mathrm{IEP}: 1,653)}=26.5, p<0.0001$; right: $t=3.3, p=0.016$; unpaired $t$ test). A significant difference in CCEP amplitude between channels showing IEP suppression or IEP potentiation was observed in S1, S2, and S3 (Fig. 7F; Mann-Whitney $U$ test, $p<$ $0.05)$.

Repetitive motor and temporal stimulation also produces changes that outlast the stimulation period and in predictable brain regions

To test the generalizability of our findings, we examined the effect of repetitive $10 \mathrm{~Hz}$ stimulation in motor and temporal cortices in a separate cohort. In all four of these subjects, CCEP amplitudes were suppressed following $10 \mathrm{~Hz}$ stimulation (Fig. 8). Regions with high CCEP amplitude roughly corresponded to regions that were modulated following stimulation. In subjects receiving stimulation to the motor (S5-S7) and temporal cortex, the suppression of CCEP amplitude was observed local to the stimulation site. For both motor and temporal cortex stimulation, CCEP amplitude suppression was prominent immediately following stimulation, with a gradual return to baseline after $\sim 10 \mathrm{~min}$. The exception to this was S7, who did not show immediate CCEP amplitude suppression. Due to low number of channels modulated following motor stimulation, we pooled the data from S5-S7 for further analysis. We found that modulated channels demonstrate higher prestimulation CCEP amplitude and were closer to the stimulation site than the nonmodulated regions (Fig. 9A,B; MannWhitney $U$ test; $p<0.001)$. However, modulated channels did not differ in prestimulation CCEP latency compared with nonmodulated channels with motor cortex stimulation (Fig. 9C; Mann-Whitney $U$ test; $p_{\text {motor }}=0.10$ ), whereas modulated channels after temporal cortex stimulation had higher prestimulation CCEP latency (Fig. 9C; $p_{\text {temporal }}<0.001$ ). Similar to prefrontal stimulation findings, adding prestimulation CCEP amplitude and latency to distance in a regression model led to improved adjusted $R^{2}$ in explaining the strength of excitability change following motor and temporal cortex stimulation (Table 3). Three subjects (S5-S7) demonstrated a $>25 \%$ increase in adjusted $R^{2}$ by incorporating functional baseline features. A binary classifier incorporating these prestimulation variables predicted regions of modulation with $88 \%$ accuracy, 89 (77-96) AUC in patients with motor cortex stimulation and $72 \%$ accuracy, 81 (74-87) AUC in patients with temporal cortex stimulation (Fig. 9D). A range of sensitivity and specificity values are outlined for this group (Table 4).

\section{Discussion}

\section{Summary of findings}

We investigated the neurophysiological effects of repetitive electrical stimulation in humans in a manner thought to induce potentiation when applied noninvasively. Prefrontal stimulation $(n=4)$ induced both local and distal excitability changes in a subset (12\%) of regions measured, with some consistent predictive characteristics. Stimulation elicited excitability change (1) in regions anatomically closer and functionally connected to the stimulation site, (2) in the form of potentiation and depression, and (3) in both early and late CCEP components. We demonstrate high accuracy (72-95\%) and discriminability (81-99\%) in predicting regions of excitability changes using individual subjects' prestimulation connectivity profile, and show that adding prestimulation functional measures after accounting for distance to the stimulation site significantly improved model performance. We found similar results in an independent dataset of four patients undergoing either motor or temporal cortex stimulation. Last, intrastimulation evoked potentials exhibited partial consistency with the findings on pre/post CCEP testing, and revealed unique cortical regions undergoing short-term excitability changes.

\section{Mechanism underlying cortical excitability changes}

This work provides further evidence that $10 \mathrm{~Hz}$ stimulation in human nonmotor cortex produces heterogeneous excitability changes that are likely subject dependent. Early neuroimaging studies demonstrated that high-frequency prefrontal rTMS increased regional cerebral blood locally but with variable effects at other cortical regions (Speer et al., 2000; Catafau et al., 2001; Nahas et al., 2001). Following a single session of repetitive stimulation, we observed persistent CCEP changes. These effects lasted for at least $10 \mathrm{~min}$ in all subjects, and in one subject who underwent both 1 and 10 

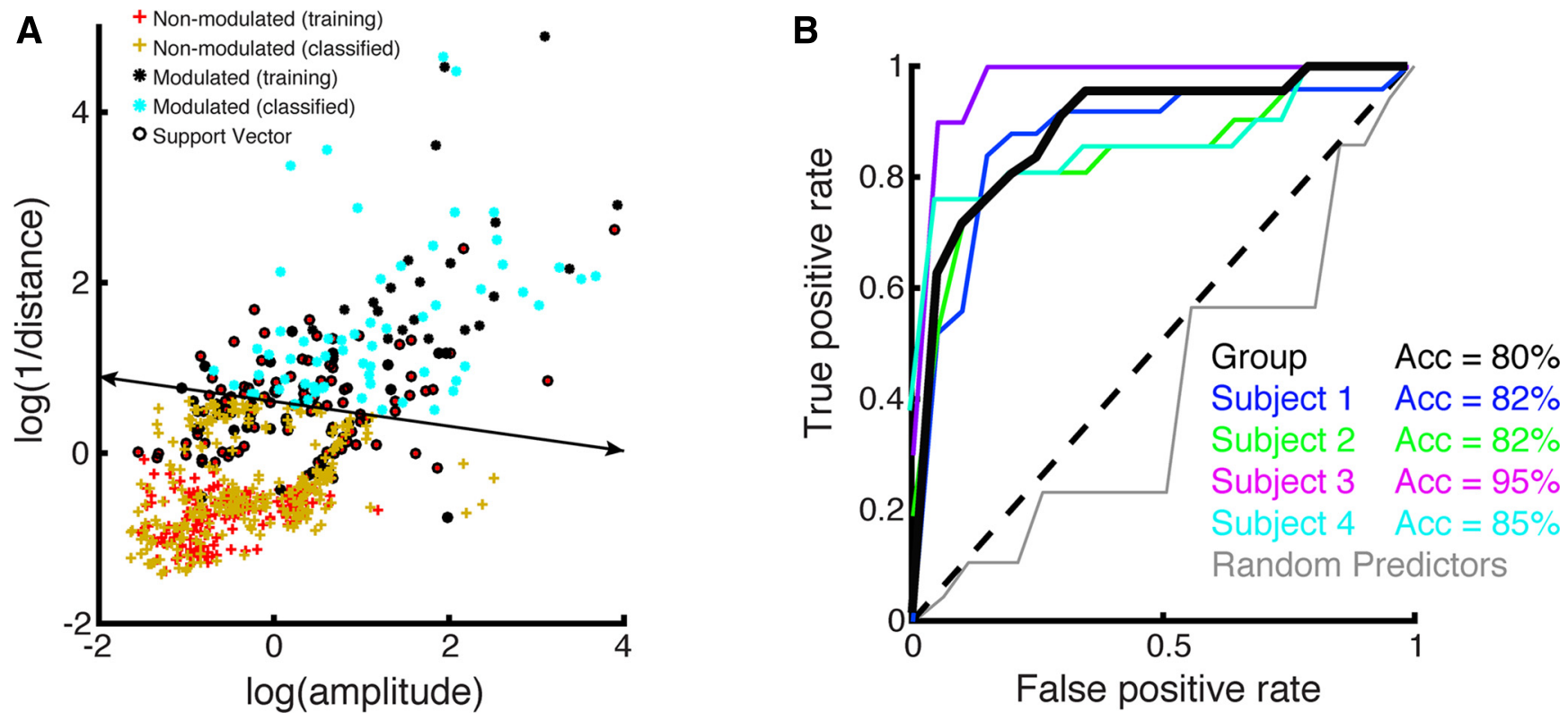

Figure 4. Anatomical and functional connectivity predicted location of excitability effects. $A$, Training and support vector data. Both features are log-normalized before classifier training and testing. The hyperplane line separates the modulated and nonmodulated data. Predictors were standardized to a mean of 0 and SD of 1. B, Single-subject and group ROC using prestimulation features to predict regions undergoing excitability changes. Accuracy of classifier is noted in the legend. Diagonal line represents chance.

Table 5. Effect of varying predictor threshold on sensitivity and specificity of the classification model

\begin{tabular}{|c|c|c|c|c|}
\hline $\begin{array}{l}\text { Distance } \\
\text { threshold, mm }\end{array}$ & $\begin{array}{l}\text { Amplitude } \\
\text { threshold, } \mu \mathrm{V}\end{array}$ & $\begin{array}{l}\text { Latency } \\
\text { threshold, ms }\end{array}$ & Sensitivity & Specificity \\
\hline \multicolumn{5}{|c|}{ S1-S4 Prefrontal Cortex: distance + amplitude + latency } \\
\hline 89 & 19 & 48 & 100 & 15 \\
\hline 42 & 35 & 36 & 84 & 70 \\
\hline 29 & 566 & 13 & 60 & 95 \\
\hline 7 & 310 & 20 & 14 & 100 \\
\hline \multicolumn{5}{|c|}{ S5-7 Motor Cortex: distance + amplitude + latency } \\
\hline 67 & 29 & 45 & 100 & 65 \\
\hline 40 & 68 & 42 & 67 & 95 \\
\hline 11 & 560 & 34 & 20 & 100 \\
\hline \multicolumn{5}{|c|}{ S8 Temporal Cortex: distance + amplitude + latency } \\
\hline 68 & 45 & 49 & 98 & 20 \\
\hline 47 & 92 & 58 & 54 & 90 \\
\hline
\end{tabular}

$\mathrm{Hz}$ stimulation, opposing directional effects were observed. These findings are in line with previous rTMS studies in healthy participants using EEG or fMRI (for review, see Thut and PascualLeone, 2010), suggesting potential generalizability to noninvasive stimulation.

Additionally, we found differences in the proportion of sites undergoing suppression or potentiation. Motor cortex stimulation suppressed the early A1 in all three patients, consistent with motor rTMS eliciting unidirectional effects in the MEP (Ziemann et al., 2008) and EEG potentials (Esser et al., 2006; Holler et al., 2006). However, the suppression of the A1 component, which likely represents depression of cortical connections (Dudek and Bear, 1992; Kirkwood and Bear, 1994), is in contrast with noninvasive findings. At this time, it is unclear whether the difference between this suppression and the commonly reported potentiation in noninvasive studies stem from the nature of the perturbation (electrical vs magnetic), measurement technique (CCEP vs TMS-evoked potential), or population (epilepsy vs healthy). Furthermore, prefrontal stimulation elicited A1 potentiation $(n=2)$ and suppression $(n=2)$. Given the across-subject consistency following motor cortex stimulation, the directional variability observed here is thus less likely due to differences in stimulation or recording sites but more so true variability in the manner that prefrontal cortex responds to repetitive stimulation. These results suggest high-frequency stimulation does not consistently increase cortical excitability and add to the existing evidence showing interindividual variability in cortical responsiveness to noninvasive stimulation (Cardenas-Morales et al., 2014; López-Alonso et al., 2014; Nettekoven et al., 2015).

With respect to the cortical location of excitability changes, we were able to identify modulated regions with $85 \%$ accuracy using prestimulation network features. This indicates $\sim 15 \%$ of modulated regions were either not induced within the stimulation network (false-positives) or were induced outside of it (falsenegatives), suggesting that stimulation effects are not distributed to all nodes within the network, nor are they confined to the network. Finally, for all stimulated regions, excitability changes tended to occur in one direction for a given patient. Although prestimulation features could not explain the direction of observed changes, the direction of intrastimulation changes was informative.

Finally, we note that the transient changes in evoked potentials we have observed can be understood as a form of functional plasticity; however, further investigation is necessary to determine whether and how this functional plasticity relates to cellular and synaptic change.

Intrastimulation excitability dynamics

For the first time, we demonstrate that intrastimulation changes measured intracranially can capture stimulation-induced neuronal dynamics. Across brain regions, the direction of IEP changes corresponded with the direction of CCEP changes. In particular, significant changes in IEP reflected excitability change on pre/post CCEP testing in two of four subjects. These discrepancies between subjects may be due to low signal-to-noise in the IEP signal or represent brain regions that change after stimulation as a result of intrastimulation changes in connected regions. Although intriguing, much work is needed regarding understanding the dynamics of plasticity induction before translating 
A
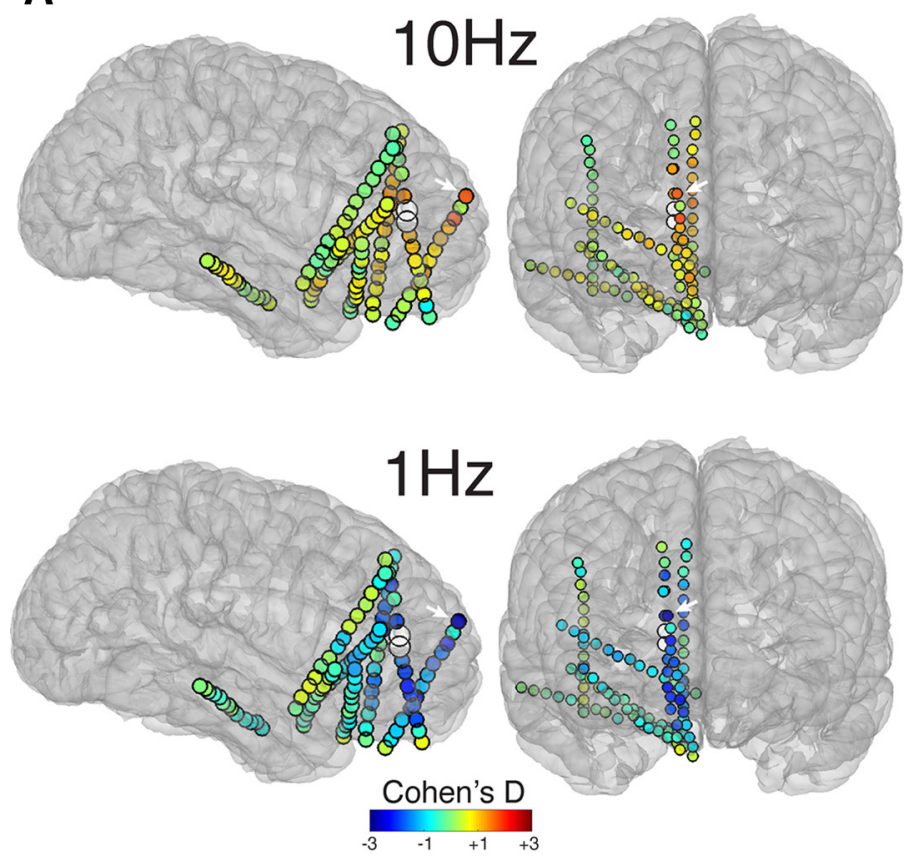

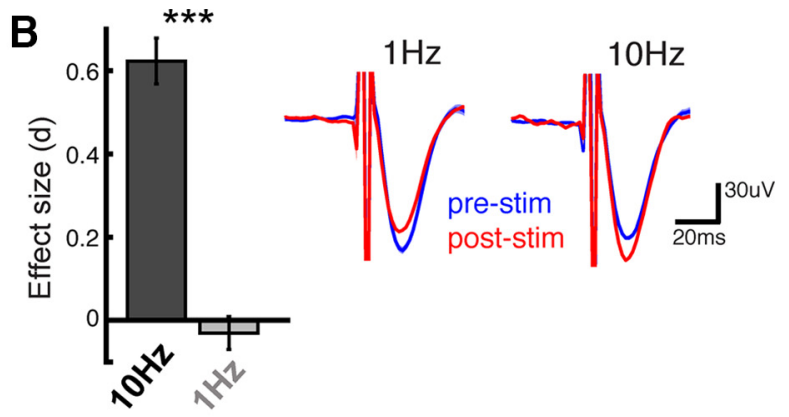

C

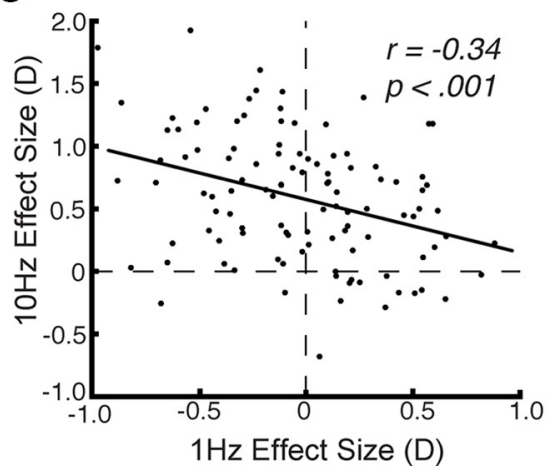

Figure 5. The direction of excitability change differed for 1 and $10 \mathrm{~Hz}$ repetitive stimulation. $A$, Effect size maps for subject 2 following 10 and $1 \mathrm{~Hz}$ stimulation. Colors represent strength of effect size change. $\boldsymbol{B}$, Left: Mean effect sizes following 10 and $1 \mathrm{~Hz}$ stimulation. Right: CCEPs pre/poststimulation from electrode in $\boldsymbol{A}$ denoted with arrows. ${ }^{* * *} p<0.001$, paired $t$ test. $\boldsymbol{C}$, Relationship of 1 and $10 \mathrm{~Hz}$ effect sizes for all electrodes.

A

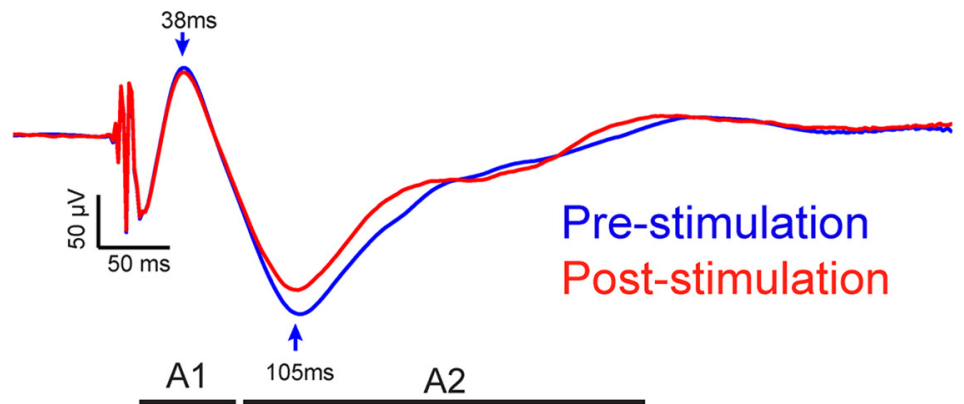

B

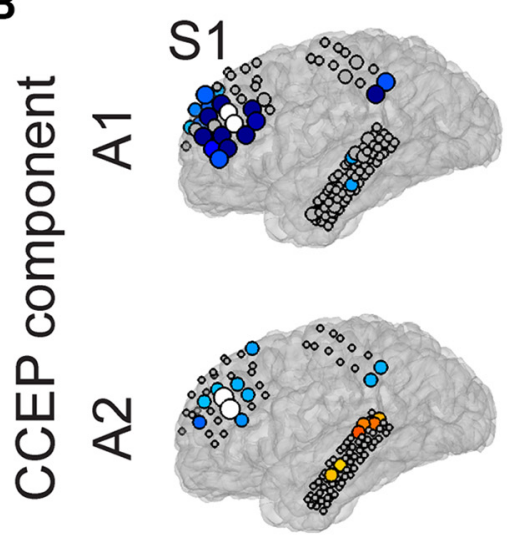

C

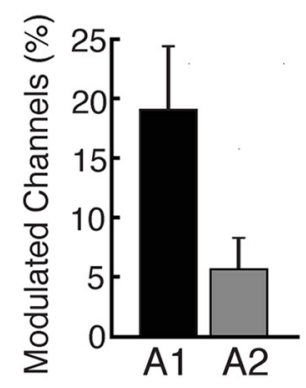

Figure 6. Excitability changes were observed more often in earlier than later CCEP components. $\boldsymbol{A}$, Example CCEP waveform before and after repetitive stimulation. Note the early sharp deflections and later slow potential. $B$, Effect size plots quantifying CCEP change during the early ( $A 1,10-60 \mathrm{~ms})$ and late (A2, 60 - 250 ms) components of the CCEP. C, Single-subject comparison between CCEP changes in the early and late CCEP components. 
A

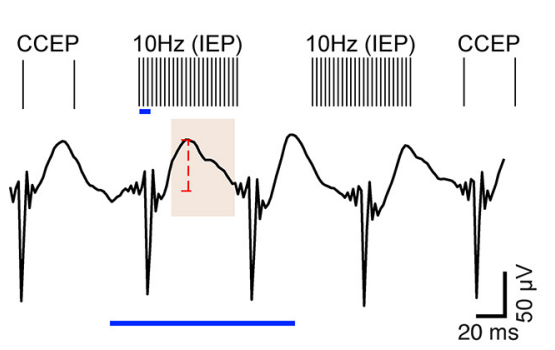

$E$
B

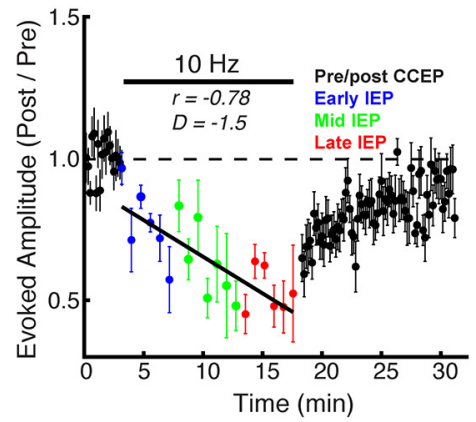

C

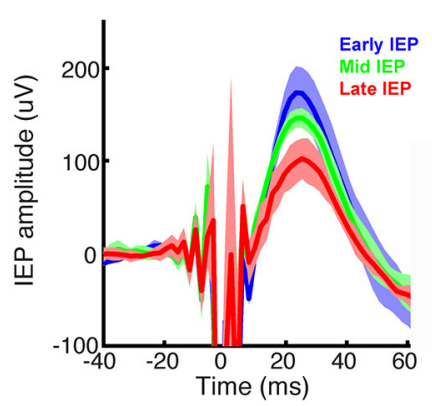

D

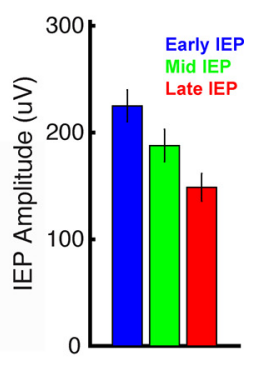

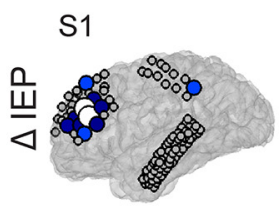
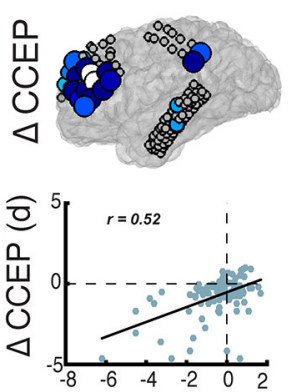

S2
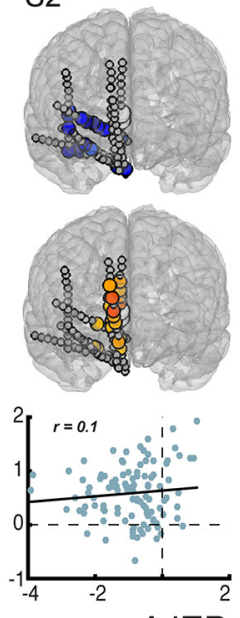

S3
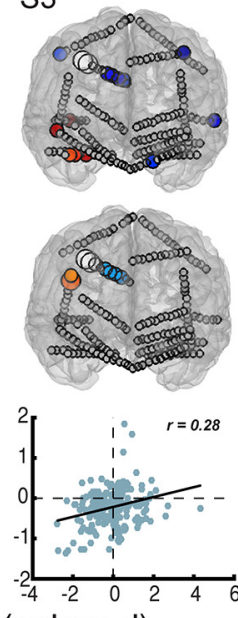

S4
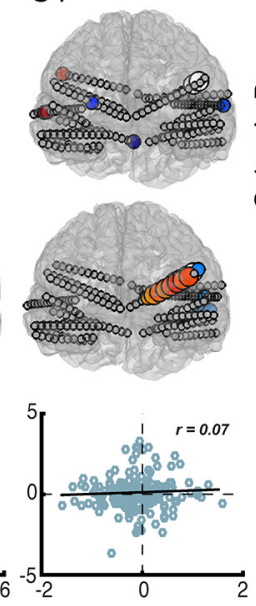
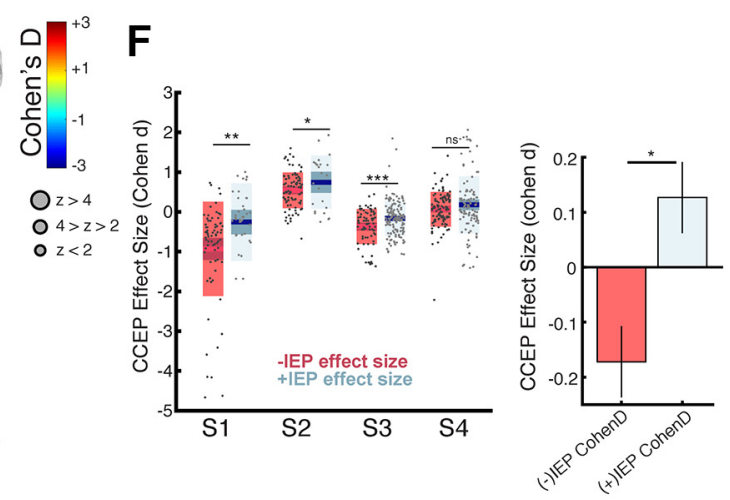

$\Delta \operatorname{IEP}($ cohen d)

Figure 7. IEP dynamics partially reflect CCEP changes observed following stimulation. $A$, Top, Schematic of temporal relationship of CCEP and IEP. Bottom, Four consecutive single-trial IEPs within a single train of pulses. Shaded area and vertical line denote the time window and peak-to-peak quantification of IEP, respectively. Scale refers to single trial IEPs only and not schematic above. $\boldsymbol{B}$, Relationship of CCEP and IEP dynamics at a single electrode. C, IEP waveform traces at beginning, middle, and end of stimulation. $\boldsymbol{D}$, Quantification of $\boldsymbol{B}$ and $\boldsymbol{C}$. $\boldsymbol{E}$, Single-subject effect size maps for IEP and CCEP. Note the similar regions of suppressed IEP and CCEP both locally and at more remote locations. $\boldsymbol{E}$, Top, Single-subject relationship of IEP and CCEP dynamics. Bottom, Relationship of IEP versus CCEP effect size for each subject. Note the weak but positive correlation between IEP dynamics and pre/post-CCEP measures. $\boldsymbol{F}$, Box plots (left) and group analysis (right) comparing IEP and CCEP effect size. ${ }^{*} p<0.05,{ }^{* *} p<0.01,{ }^{* * *} p<0.001$, Mann-Whitney $U$ test.

into treatment. Only a few studies have addressed these questions noninvasively, and have showed variable intrastimulation cortical excitability dynamics (Hamidi et al., 2010; Veniero et al., 2010). Further work is required to understand how intrastimulation cortical dynamics is related to long-lasting brain changes, which can lead to the development of novel stimulation therapies that maximize brain changes.

Toward optimization of noninvasive brain stimulation

Translating these results to noninvasive stimulation could provide principles for personalizing therapeutic stimulation. Currently, rTMS treatment for depression and other neuropsychiatric disorders apply a "one-size-fits-all" approach to target the left DLPFC by localizing motor cortex and moving anteriorly $5 \mathrm{~cm}$ (Reid et al., 1998). However, this protocol does not account for variations in individual anatomy and functional connectivity. In fact, neuronavigational efforts that target the stimulation site based on the subject's anatomy (Fitzgerald et al., 2009) or functional connections (Fox et al., 2012) suggest improved outcomes. Furthermore, Nettekoven et al. (2015) recently showed responsiveness to rTMS was partially dependent on the prestimulation network connectivity of the stimulated site. Our work demonstrates that by using prestimulation network properties (distance, CCEP amplitude and latency), we could predict (with $48 \%$ of variance explained) both the strength of plasticity and regions of signifi- cant modulation. Thus, based on the downstream circuit of interest (i.e., the frontoparietal or default mode network in depression), one could model the effect of repetitive stimulation from pretreatment characteristics and modify the stimulation site to target the network of interest. Multiple obstacles need to be overcome before implementation (see Limitations and future directions), but this approach represents an exciting path to personalized noninvasive neuromodulation.

\section{Limitations and future directions}

Although this work improves our understanding of human cortical plasticity, several important considerations limit the interpretation and generalizability of this work. First, as is true for all work in the epilepsy surgery population, access to direct recordings in awake humans does not come without cost, because generalizing from these patients is difficult. Our sample size is small, patients were heterogeneous with respect to seizure onset and implant type, and the seizure focus and early epileptic spread regions can affect local and global brain excitability and connectivity (Pereira et al., 2010; Bettus et al., 2011; Pittau et al., 2012). Therefore, findings from this study may be skewed based on their proximity to the epileptic network. A larger follow-up study comparing the direction and duration of plasticity effects to the proximity and severity of the epileptic network is warranted. Second, we could not exclude the possibility of homeostatic plasticity in 


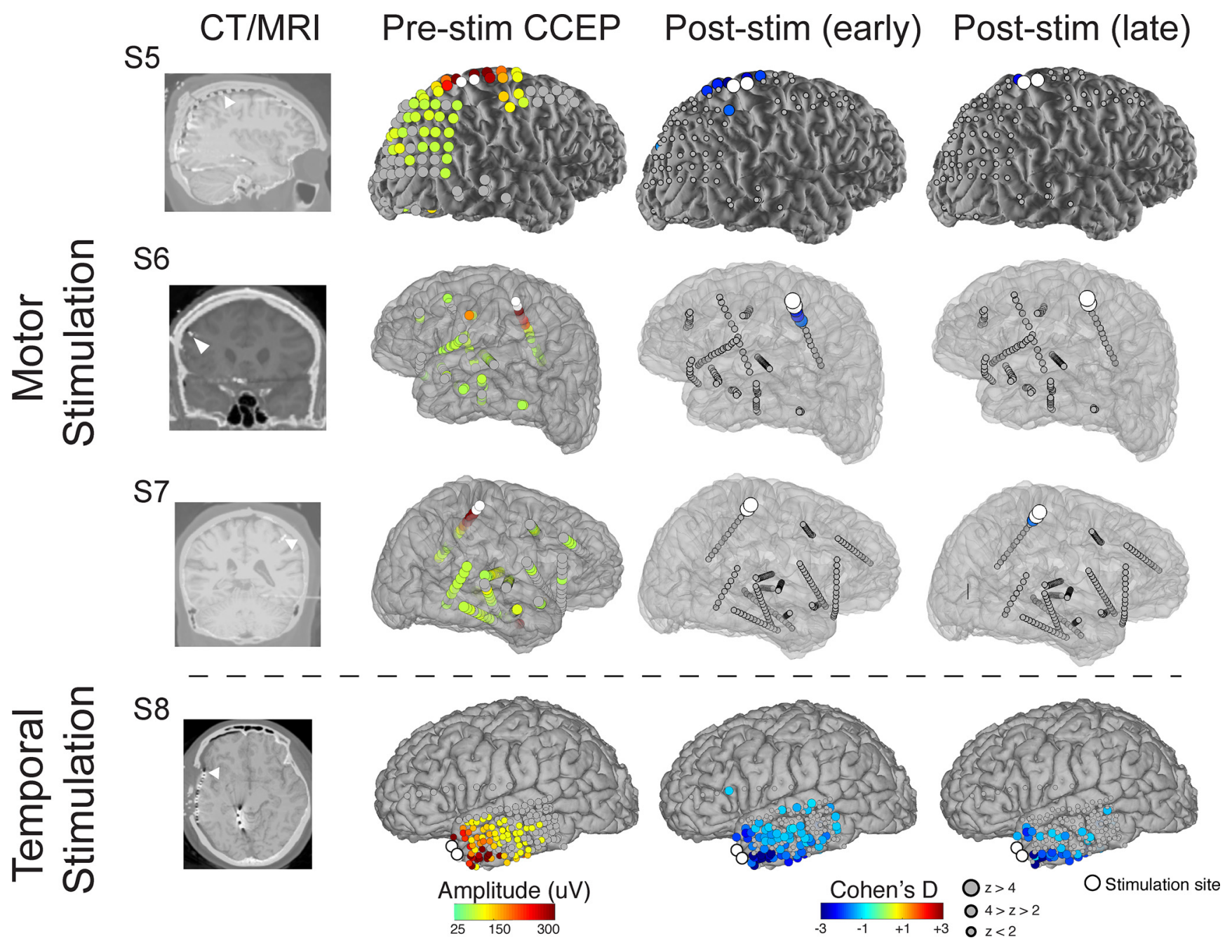

Figure 8. Repetitive stimulation of the motor and temporal cortex also elicit CCEP changes outlasting the stimulation. Brain plots showing topography of prestimulation CCEP amplitude and poststimulation (early and late) change in CCEPs in subjects undergoing motor cortex stimulation $(n=3)$ and temporal cortex stimulation $(n=1)$. Colors of each electrode for the brain plots show prestimulation CCEP as high (red colors) or low (green colors) and poststimulation changes as positive (warm colors) or negative (colder colors) effect sizes. Left, Preoperative MRI coregistered with postoperative CT (stimulation site denoted by arrow). Electrodes showing effect sizes were thresholded using 5\% FDR correction for multiple comparisons, with gray electrodes showing channels with nonsignificant changes. Electrode size represents the magnitude of $z$-score relative to a normal distribution (see key).

A

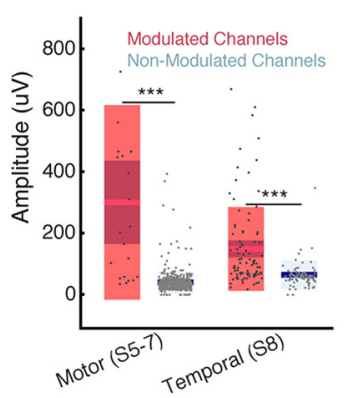

B

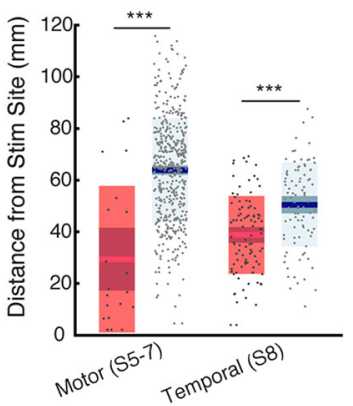

C

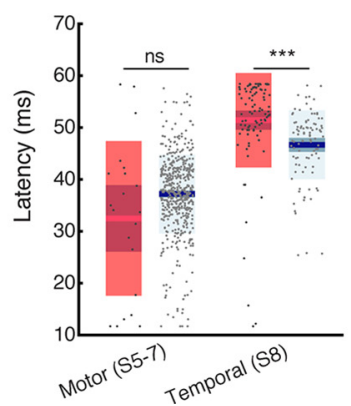

D

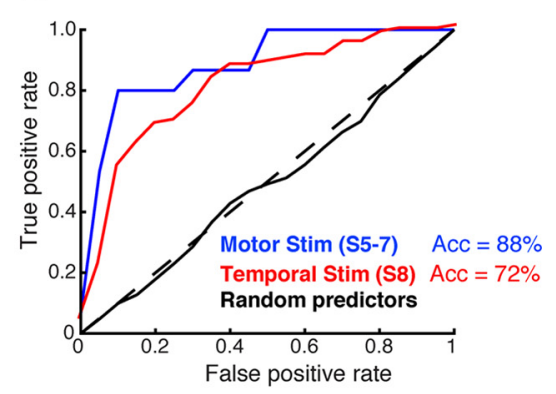

Figure 9. Anatomical and functional connectivity predict modulated regions in both motor and temporal stimulation. $\boldsymbol{A}-\boldsymbol{C}$, Boxplots showing relationship between whether an electrode is modulated and its prestimulation $(\boldsymbol{A})$ amplitude, $(\boldsymbol{B})$ distance, and $(\boldsymbol{C})$ latency for motor $(n=3)$ and temporal cortex stimulation $(n=1)$. Data for the three patients with motor cortex stimulation were pooled before analysis. $\boldsymbol{D}, \mathrm{ROC}$ using prestimulation features to predict regions undergoing excitability changes following motor cortex stimulation or temporal cortex stimulation. Diagonal line represents chance. ${ }^{*} p<0.05,{ }^{* *} p<0.01,{ }^{* * *} p<0.001$, Mann-Whitney $U$ test.

this study. Previous work showed that a priming stimulation period before repetitive stimulation modifies the effects of brain stimulation (Siebner et al., 2004; Pötter-Nerger et al., 2009). Specifically, preconditioning with transcranial direct current (tDCS) can change the direction of the rTMS-induced changes in the motor cortex (Lang et al., 2004; Siebner et al., 2004) and to a lesser extent in the visual cortex (Lang et al., 2007). This homeostatic mechanism is postulated to stabilize neuronal activity when plasticity-indu- 
cing interventions are administered in close sequence (for review, see Karabanov et al., 2015). The excitability effects of $10 \mathrm{~Hz}$ stimulation observed in our study could be modulated by the prestimulation CCEP test pulses, thus limiting our conclusions regarding the intrinsic effects of $10 \mathrm{~Hz}$ stimulation. Third, due the absence of sham control, plasticity may be affected by subject fatigue during stimulation. Studies measuring TMS-evoked potentials and CCEP demonstrated marked cortical excitability changes during the transition to sleep (Massimini et al., 2005; Pigorini et al., 2015). Our subjects were monitored to ensure they did not fall asleep during stimulation, though it remains possible subtle fatigue may alter cortical excitability. In the study by Pigorini et al. (2015) CCEPs exhibited a change in waveform morphology during sleep compared with wakefulness, which was not observed in our analysis, suggesting less of a confound in our study. Fourth, time constraints within this surgical population (typically $\sim 1 \mathrm{~h}$ per subject) limit the ability to perform control experiments including additional $1 \mathrm{~Hz}$ stimulation, stimulation across multiple days, and stimulation of sites both within and outside the network of interest. Fifth, the spatial spread and depth penetration induced by stimulation has been described previously, but was not performed in this study (Butson et al., 2006; Xie et al., 2006; for review, see Yousif and Liu, 2007). Future work applying electrical field modeling would improve the interpretability of stimulation effects. Last, measuring resting state or task-induced coherence could increase interpretability and may provide additional information on predicting long-term plasticity. Additionally, the behavioral effects of stimulation was not measured in our study. This warrants further investigation with mood self-reports (Woźniak-Kwaśniewska et al., 2014) and other behavioral and state-dependent measures that target the DLPFC.

\section{References}

Bakker N, Shahab S, Giacobbe P, Blumberger DM, Daskalakis ZJ, Kennedy SH, Downar J (2015) rTMS of the dorsomedial prefrontal cortex for major depression: safety, tolerability, effectiveness, and outcome predictors for $10 \mathrm{~Hz}$ versus intermittent theta-burst stimulation. Brain Stimul 8:208-215. CrossRef Medline

Barr MS, Farzan F, Rusjan PM, Chen R, Fitzgerald PB, Daskalakis ZJ (2009) Potentiation of gamma oscillatory activity through repetitive transcranial magnetic stimulation of the dorsolateral prefrontal cortex. Neuropsychopharmacology 34:2359-2367. CrossRef Medline

Bettus G, Ranjeva JP, Wendling F, Bénar CG, Confort-Gouny S, Régis J, Chauvel P, Cozzone PJ, Lemieux L, Bartolomei F, Guye M (2011) Interictal functional connectivity of human epileptic networks assessed by intracerebral EEG and BOLD signal fluctuations. PloS One 6:e20071. CrossRef Medline

Bliss TV, Lomo T (1973) Long-lasting potentiation of synaptic transmission in the dentate area of the anaesthetized rabbit following stimulation of the perforant path. J Physiol 232:331-356. CrossRef Medline

Butson CR, Maks CB, McIntyre CC (2006) Sources and effects of electrode impedance during deep brain stimulation. Clin Neurophysiol 117:447454. CrossRef Medline

Cárdenas-Morales L, Volz LJ, Michely J, Rehme AK, Pool EM, Nettekoven C, Eickhoff SB, Fink GR, Grefkes C (2014) Network connectivity and individual responses to brain stimulation in the human motor system. Cereb Cortex 24:1697-1707. CrossRef Medline

Catafau AM, Perez V, Gironell A, Martin JC, Kulisevsky J, Estorch M, Carrió I, Alvarez E (2001) SPECT mapping of cerebral activity changes induced by repetitive transcranial magnetic stimulation in depressed patients: a pilot study. Psychiatry Res 106:151-160. CrossRef Medline

Cohen J (1998) Statistical power analysis for the behavioral sciences. Hillsdale, NJ: Lawrence Erlbaum.

Cortes C, Vapnik V (1995) Support-vector networks. Machine Learning 20: 273. CrossRef

Cousineau D (2005) Confidence intervals in within-subject designs: a simpler solution to loftus and Masson's method. TuTutor Quant Methods Psychol 1:42-45. CrossRef
Dale AM, Fischl B, Sereno MI (1999) Cortical surface-based analysis: I. segmentation and surface reconstruction. Neuroimage 9:179-194. CrossRef Medline

David O, Woźniak A, Minotti L, Kahane P (2008) Preictal short-term plasticity induced by intracerebral $1 \mathrm{~Hz}$ stimulation. Neuroimage 39:16331646. CrossRef Medline

David O, Job AS, De Palma L, Hoffmann D, Minotti L, Kahane P (2013) Probabilistic functional tractography of the human cortex. Neuroimage 80:307-317. CrossRef Medline

Douglas RM (1977) Long lasting synaptic potentiation in the rat dentate gyrus following brief high frequency stimulation. Brain Res 126:361-365. CrossRef Medline

Dudek SM, Bear MF (1992) Homosynaptic long-term depression in area CA1 of hippocampus and effects of $N$-methyl-D-aspartate receptor blockade. Proc Natl Acad Sci U S A 89:4363-4367. CrossRef Medline

Duncan JS, Papademetris X, Yang J, Jackowski M, Zeng X, Staib LH (2004) Geometric strategies for neuroanatomic analysis from MRI. Neuroimage 23:S34-S45. CrossRef Medline

Dykstra AR, Chan AM, Quinn BT, Zepeda R, Keller CJ, Cormier J, Madsen JR, Eskandar EN, Cash SS (2012) Individualized localization and cortical surface-based registration of intracranial electrodes. Neuroimage 59: 3563-3570. CrossRef Medline

Eldaief MC, Halko MA, Buckner RL, Pascual-Leone A (2011) Transcranial magnetic stimulation modulates the brain's intrinsic activity in a frequencydependent manner. Proc Natl Acad Sci U S A 108:21229-21234. CrossRef Medline

Entz L, Tóth E, Keller CJ, Bickel S, Groppe DM, Fabó D, Kozák LR, Erőss L, Ulbert I, Mehta AD (2014) Evoked effective connectivity of the human neocortex. Hum Brain Mapp 35:5736-5753. CrossRef Medline

Esser SK, Huber R, Massimini M, Peterson MJ, Ferrarelli F, Tononi G (2006) A direct demonstration of cortical LTP in humans: a combined TMS/EEG study. Brain Res Bull 69:86-94. CrossRef Medline

Esslinger C, Schüler N, Sauer C, Gass D, Mier D, Braun U, Ochs E, Schulze TG, Rietschel M, Kirsch P, Meyer-Lindenberg A (2014) Induction and quantification of prefrontal cortical network plasticity using $5 \mathrm{~Hz}$ rTMS and fMRI. Hum Brain Mapp 35:140-151. CrossRef Medline

Fischl B, van der Kouwe A, Destrieux C, Halgren E, Ségonne F, Salat DH, Busa E, Seidman LJ, Goldstein J, Kennedy D, Caviness V, Makris N, Rosen B, Dale AM (2004) Automatically parcellating the human cerebral cortex. Cereb Cortex 14:11-22. CrossRef Medline

Fitzgerald PB, Fountain S, Daskalakis ZJ (2006) A comprehensive review of the effects of rTMS on motor cortical excitability and inhibition. Clin Neurophysiol 117:2584-2596. CrossRef Medline

Fitzgerald PB, Hoy K, McQueen S, Maller JJ, Herring S, Segrave R, Bailey M, Been G, Kulkarni J, Daskalakis ZJ (2009) A randomized trial of rTMS targeted with MRI based neuro-navigation in treatment-resistant depression. Neuropsychopharmacology 34:1255-1262. CrossRef Medline

Fox MD, Buckner RL, White MP, Greicius MD, Pascual-Leone A (2012) Efficacy of transcranial magnetic stimulation targets for depression is related to intrinsic functional connectivity with the subgenual cingulate. Biol Psychiatry 72:595-603. CrossRef Medline

Funke K, Benali A (2011) Modulation of cortical inhibition by rTMS: findings obtained from animal models. J Physiol 589:4423-4435. CrossRef Medline

Griskova I, Ruksenas O, Dapsys K, Herpertz S, Höppner J (2007) The effects of $10 \mathrm{~Hz}$ repetitive transcranial magnetic stimulation on resting EEG power spectrum in healthy subjects. Neurosci Lett 419:162-167. CrossRef Medline

Groppe DM, Bickel S, Dykstra AR, Wang X, Megevand P, Mercier MR, Lado FA, Mehta AD, Honey CJ (2017) iELVis: an open source MATLAB toolbox for localizing and visualizing human intracranial electrode data. J Neurosci Methods 281:40-48.

Halko MA, Farzan F, Eldaief MC, Schmahmann JD, Pascual-Leone A (2014) Intermittent theta-burst stimulation of the lateral cerebellum increases functional connectivity of the default network. J Neurosci 34:1204912056. CrossRef Medline

Hamidi M, Slagter HA, Tononi G, Postle BR (2010) Brain responses evoked by high-frequency repetitive transcranial magnetic stimulation: an eventrelated potential study. Brain Stimul 3:2-14. CrossRef Medline

Holler I, Siebner HR, Cunnington R, Gerschlager W (2006) 5 Hz repetitive TMS increases anticipatory motor activity in the human cortex. Neurosci Lett 392:221-225. CrossRef Medline 
Karabanov A, Ziemann U, Hamada M, George MS, Quartarone A, Classen J, Massimini M, Rothwell J, Siebner HR (2015) Consensus paper: probing homeostatic plasticity of human cortex with non-invasive transcranial brain stimulation. Brain Stimul 8:993-1006. CrossRef Medline

Keller CJ, Bickel S, Entz L, Ulbert I, Milham MP, Kelly C, Mehta AD (2011) Intrinsic functional architecture predicts electrically evoked responses in the human brain. Proc Natl Acad Sci U S A 108:10308-10313. CrossRef Medline

Keller CJ, Bickel S, Honey CJ, Groppe DM, Entz L, Craddock RC, Lado FA, Kelly C, Milham M, Mehta AD (2013) Neurophysiological investigation of spontaneous correlated and anticorrelated fluctuations of the BOLD signal. J Neurosci 33:6333-6342. CrossRef Medline

Keller CJ, Honey CJ, Mégevand P, Entz L, Ulbert I, Mehta AD (2014a) Mapping human brain networks with cortico-cortical evoked potentials. Philos Trans R Soc Lond B Biol Sci 369:20130528. CrossRef Medline

Keller CJ, Honey CJ, Entz L, Bickel S, Groppe DM, Toth E, Ulbert I, Lado FA, Mehta AD (2014b) Corticocortical evoked potentials reveal projectors and integrators in human brain networks. J Neurosci 34:9152-9163. CrossRef Medline

Keller CJ, Davidesco I, Megevand P, Lado FA, Malach R, Mehta AD (2017) Tuning face perception with electrical stimulation of the fusiform gyrus. Hum Brain Mapp 38:2830-2842. CrossRef Medline

Kirkwood A, Bear MF (1994) Homosynaptic long-term depression in the visual cortex. J Neurosci 14:3404-3412. CrossRef Medline

Koubeissi MZ, Lesser RP, Sinai A, Gaillard WD, Franaszczuk PJ, Crone NE (2012) Connectivity between perisylvian and bilateral basal temporal cortices. Cereb Cortex 22:918-925. CrossRef Medline

Kubota Y, Enatsu R, Gonzalez-Martinez J, Bulacio J, Mosher J, Burgess RC, Nair DR (2013) In vivo human hippocampal cingulate connectivity: a corticocortical evoked potentials (CCEPs) study. Clin Neurophysiol 124: 1547-1556. CrossRef Medline

Lang N, Siebner HR, Ernst D, Nitsche MA, Paulus W, Lemon RN, Rothwell JC (2004) Preconditioning with transcranial direct current stimulation sensitizes the motor cortex to rapid-rate transcranial magnetic stimulation and controls the direction of after-effects. Biol Psychiatry 56:634-639. CrossRef Medline

Lang N, Siebner HR, Chadaide Z, Boros K, Nitsche MA, Rothwell JC, Paulus W, Antal A (2007) Bidirectional modulation of primary visual cortex excitability: a combined tDCS and rTMS study. Invest Ophthalmol Vis Sci 48:5782-5787. CrossRef Medline

López-Alonso V, Cheeran B, Río-Rodríguez D, Fernández-Del-Olmo M (2014) Inter-individual variability in response to non-invasive brain stimulation paradigms. Brain Stimul 7:372-380. CrossRef Medline

Massimini M, Ferrarelli F, Huber R, Esser SK, Singh H, Tononi G (2005) Breakdown of cortical effective connectivity during sleep. Science 309: 2228-2232. CrossRef Medline

Matsumoto R, Nair DR, Ikeda A, Fumuro T, Lapresto E, Mikuni N, Bingaman W, Miyamoto S, Fukuyama H, Takahashi R, Najm I, Shibasaki H, Lüders HO (2012) Parieto-frontal network in humans studied by cortico-cortical evoked potential. Hum Brain Mapp 33:2856-2872. CrossRef Medline

Matsumoto R, Nair DR, LaPresto E, Bingaman W, Shibasaki H, Lüders HO Functional connectivity in human cortical motor system: a corticocortical evoked potential study. Matsumoto R1, Nair DR, LaPresto E, Bingaman W, Shibasaki H, Lüders HO (2007) Functional connectivity in human cortical motor system: a cortico-cortical evoked potential study. Brain 130(Pt 1):181-97. CrossRef Medline

Matsumoto R, Nair DR, LaPresto E, Najm I, Bingaman W, Shibasaki H, Lüders HO (2004) Functional connectivity in the human language system: a cortico-cortical evoked potential study. Brain 127:2316-2330. CrossRef Medline

McClintock SM, Reti IM, Carpenter LL, McDonald WM, Dubin M, Taylor SF, Cook IA, O'Reardon J, Husain MM, Wall C, Krystal AD, Sampson SM, Morales O, Nelson BG, Latoussakis V, George MS, Lisanby SH; National Network of Depression Centers rTMS Task Group; American Psychiatric Association Council on Research Task Force on Novel B, Treatments (2018) Consensus recommendations for the clinical application of repetitive transcranial magnetic stimulation (rTMS) in the treatment of depression. J Clin Psychiatry 79:16cs10905. CrossRef Medline

Mehta AD, Klein G (2010) Clinical utility of functional magnetic resonance imaging for brain mapping in epilepsy surgery. Epilepsy Res 89:126-132. CrossRef Medline

Mulkey RM, Malenka RC (1992) Mechanisms underlying induction of ho- mosynaptic long-term depression in area CA1 of the hippocampus. Neuron 9:967-975. Medline

Nahas Z, Teneback CC, Kozel A, Speer AM, DeBrux C, Molloy M, Stallings L, Spicer KM, Arana G, Bohning DE, Risch SC, George MS (2001) Brain effects of TMS delivered over prefrontal cortex in depressed adults: role of stimulation frequency and coil-cortex distance. J Neuropsychiatry Clin Neurosci 13:459-470. CrossRef Medline

Nettekoven C, Volz LJ, Leimbach M, Pool EM, Rehme AK, Eickhoff SB, Fink GR, Grefkes C (2015) Inter-individual variability in cortical excitability and motor network connectivity following multiple blocks of rTMS. Neuroimage 118:209-218. CrossRef Medline

O'Reardon JP, Peshek AD, Romero R, Cristancho P (2006) Neuromodulation and transcranial mag netic stimulation (TMS): a 21st century paradigm for therapeutics in psychiatry. Psychiatry (Edgmont) 3:30-40. Medline

Pell GS, Roth Y, Zangen A (2011) Modulation of cortical excitability induced by repetitive transcranial magnetic stimulation: influence of timing and geometrical parameters and underlying mechanisms. Prog Neurobiol 93:59-98. CrossRef Medline

Pereira FR, Alessio A, Sercheli MS, Pedro T, Bilevicius E, Rondina JM, Ozelo HF, Castellano G, Covolan RJ, Damasceno BP, Cendes F (2010) Asymmetrical hippocampal connectivity in mesial temporal lobe epilepsy: evidence from resting state fMRI. BMC Neurosci 11:66. CrossRef Medline

Pigorini A, Sarasso S, Proserpio P, Szymanski C, Arnulfo G, Casarotto S, Fecchio M, Rosanova M, Mariotti M, Lo Russo G, Palva JM, Nobili L, Massimini M (2015) Bistability breaks-off deterministic responses to intracortical stimulation during non-REM sleep. Neuroimage 112:105113. CrossRef Medline

Pittau F, Grova C, Moeller F, Dubeau F, Gotman J (2012) Patterns of altered functional connectivity in mesial temporal lobe epilepsy. Epilepsia 53: 1013-1023. CrossRef Medline

Pötter-Nerger M, Fischer S, Mastroeni C, Groppa S, Deuschl G, Volkmann J, Quartarone A, Münchau A, Siebner HR (2009) Inducing homeostaticlike plasticity in human motor cortex through converging corticocortical inputs. J Neurophysiol 102:3180-3190. CrossRef Medline

Reid PD, Shajahan PM, Glabus MF, Ebmeier KP (1998) Transcranial magnetic stimulation in depression. Br J Psychiatry 173:449-452. CrossRef Medline

Rossi S, Hallett M, Rossini PM, Pascual-Leone A; Safety of TMS Consensus Group (2009) Safety, ethical considerations, and application guidelines for the use of transcranial magnetic stimulation in clinical practice and research. Clin Neurophysiol 120:2008-2039. CrossRef Medline

Rounis E, Lee L, Siebner HR, Rowe JB, Friston KJ, Rothwell JC, Frackowiak RS (2005) Frequency specific changes in regional cerebral blood flow and motor system connectivity following rTMS to the primary motor cortex. Neuroimage 26:164-176. CrossRef Medline

Rounis E, Stephan KE, Lee L, Siebner HR, Pesenti A, Friston KJ, Rothwell JC, Frackowiak RS (2006) Acute changes in frontoparietal activity after repetitive transcranial magnetic stimulation over the dorsolateral prefrontal cortex in a cued reaction time task. J Neurosci 26:9629-9638. CrossRef Medline

Siebner HR, Peller M, Willoch F, Minoshima S, Boecker H, Auer C, Drzezga A, Conrad B, Bartenstein P (2000) Lasting cortical activation after repetitive TMS of the motor cortex: a glucose metabolic study. Neurology 54:956-963. CrossRef Medline

Siebner HR, Lang N, Rizzo V, Nitsche MA, Paulus W, Lemon RN, Rothwell JC (2004) Preconditioning of low-frequency repetitive transcranial magnetic stimulation with transcranial direct current stimulation: evidence for homeostatic plasticity in the human motor cortex. J Neurosci 24:3379-3385. CrossRef Medline

Skrede KK, Malthe-Sørenssen D (1981) Increased resting and evoked release of transmitter following repetitive electrical tetanization in hippocampus: a biochemical correlate to long-lasting synaptic potentiation. Brain Res 208:436-441. CrossRef Medline

Speer AM, Kimbrell TA, Wassermann EM, D Repella J, Willis MW, Herscovitch P, Post RM (2000) Opposite effects of high and low frequency rTMS on regional brain activity in depressed patients. Biol Psychiatry 48:1133-1141. CrossRef Medline

Takano B, Drzezga A, Peller M, Sax I, Schwaiger M, Lee L, Siebner HR (2004) Short-term modulation of regional excitability and blood flow in human motor cortex following rapid-rate transcranial magnetic stimulation. Neuroimage 23:849-859. CrossRef Medline 
Tang A, Thickbroom G, Rodger J (2015) Repetitive transcranial magnetic stimulation of the brain: mechanisms from animal and experimental models. Neuroscientist 23:82-94. CrossRef Medline

Thut G, Pascual-Leone A (2010) A review of combined TMS-EEG studies to characterize lasting effects of repetitive TMS and assess their usefulness in cognitive and clinical neuroscience. Brain Topogr 22:219-232. CrossRef Medline

Veniero D, Maioli C, Miniussi C (2010) Potentiation of short-latency cortical responses by high-frequency repetitive transcranial magnetic stimulation. J Neurophysiol 104:1578-1588. CrossRef Medline

Wang JX, Rogers LM, Gross EZ, Ryals AJ, Dokucu ME, Brandstatt KL, Hermiller MS, Voss JL (2014) Targeted enhancement of cortical-hippocampal brain networks and associative memory. Science 345:1054-1057. CrossRef Medline

Woźniak-Kwaśniewska A, Szekely D, Aussedat P, Bougerol T, David O (2014) Changes of oscillatory brain activity induced by repetitive trans- cranial magnetic stimulation of the left dorsolateral prefrontal cortex in healthy subjects. Neuroimage 88:91-99. CrossRef Medline

Xie K, Wang S, Aziz TZ, Stein JF, Liu X (2006) The physiologically modulated electrode potentials at the depth electrode-brain interface in humans. Neurosci Lett 402:238-243. CrossRef Medline

Yekutieli D, Benjamini Y (1999) Resampling-based false discovery rate controlling multiple test procedures for multiple testing procedures. J Stat Plan Inf 4:171-196. CrossRef

Yousif N, Liu X (2007) Modeling the current distribution across the depth electrode-brain interface in deep brain stimulation. Expert Rev Med Devices 4:623-631. CrossRef Medline

Ziemann U, Paulus W, Nitsche MA, Pascual-Leone A, Byblow WD, Berardelli A, Siebner HR, Classen J, Cohen LG, Rothwell JC (2008) Consensus: motor cortex plasticity protocols. Brain Stimul 1:164-182. CrossRef 